\title{
The Limits to Credit Growth: Mitigation Policies and Macroprudential Regulations to Foster Macrofinancial Stability and Sustainable Debt*
}

\author{
Sander van der $\operatorname{Hoog}^{a}$
}

November 2, 2017

\begin{abstract}
In this paper we study an economy with a high degree of financialization in which (nonfinancial) firms need loans from commercial banks to finance production, service debt, and make long-term investments. Along the business cycle, the economy follows a Minsky base cycle with firms traversing through the various stages of financial fragility, i.e. hedge, speculative and Ponzi finance (cf., Minsky, 1978, 1986, 1992). In the speculative financial stage cash flows are insufficient to finance the repayment of principle but sufficient for paying interest, so banks are willing to roll-over credits in order to prevent loan defaults. In the Ponzi financial position even interest payments cannot be served, but banks my still be willing to keep firms alive through "extend and pretend" loans, also known as zombie-lending (Caballero et al., 2008). This lending behavior may cause credit bubbles with increasing leverage ratios. Empirical evidence suggests that recessions following such leveraging booms are more severe and can be associated to higher economic costs (Jordà et al., 2013, Schularick and Taylor, 2012).

We study macroprudential regulations aimed at: (i) the prevention and mitigation of credit bubbles, (ii) ensuring macro-financial stability, and (iii) limiting the ability of banks to create unsustainable debt bubbles. Our results show that limiting the credit growth by using a non-risk-weighted capital ratio has slightly positive effects, while using loan eligibility criteria such as cutting off funding to all financially unsound firms (speculative and Ponzi) has strong positive effects.
\end{abstract}

Key words: Macroprudential regulation; Full Reserve Banking; Full Equity Finance; Agent-Based Macroeconomics.

JEL Classification: C63, E03, G01, G28

${ }^{\star}$ This is a post-peer-review, pre-copyedit version of an article published in Computational Economics. The final publication is available at link.springer.com (https://doi.org/10.1007/s10614-017-9714-4).

Suggested citation: "van der Hoog, S. (2017), The Limits to Credit Growth: Mitigation Policies and Macroprudential Regulations to Foster Macrofinancial Stability and Sustainable Debt, Computational Economics. https://doi.org/10.1007/s10614-017-9714-4."

${ }^{a}$ Chair for Economic Theory and Computational Economics (ETACE), Dept. of Business Administration and Economics, Bielefeld University, Germany. Phone: +49 521106 5638, Fax: +49 521106 89005, E-mail: svdhoog@wiwi.uni-bielefeld.de. 


\section{Acknowledgements}

This research has received funding under Horizon 2020 grant agreement No. 649186 - Project ISIGrowth ("Innovation-fuelled, Sustainable, Inclusive Growth"). The paper has benefited from discussions at the annual meetings of the Society for Computational Economics, CEF 2013 in Vancouver and CEF 2014 in Oslo; the CeNDEF@15 Symposium in Amsterdam, October 2013; the 1st Workshop on Agent-based Macroeconomics in Bordeaux, November 2013; the 1st Joined Bordeaux-Milano Workshop on Agent-based Macroeconomics in Bordeaux, June 2015; the Post-Keynesian Economics Conference in Kansas City, September 2014; the Conference of the Eastern Economics Association in New York City, February 2015; and the participants at a seminar held at the Financial Stability Department of Bank of Canada.

I am grateful for helpful suggestions by Herbert Dawid, Domenico Delli Gatti, Sebastian Krug, Andrea Roventini, Frank Riedel, and Tania Treibich, and I am indebted to two anonymous referees for very useful criticisms and suggestions that helped improve this paper substantially. Furthermore, I acknowledge my colleagues Philipp Harting and Simon Gemkow for their substantial contributions to the development and implementation of the Eurace@Unibi model (Gemkow et al. May 2014), and for the associated R scripts for data analysis (Gemkow and van der Hoog, 2012). We made extensive use of software provided by the R Project ( R Development Core Team, 2008).

The simulations for this paper were performed using the Flexible Large-scale Agent Modelling Environment ${ }^{1}$ (FLAME ${ }^{2}$ ). The FLAME Xparser and Libmboard library are made available under the LGPL v3 (Coakley et al., 2012a).

Finally, I thank the Regional Computing Center of the University of Cologne (RRZK) for providing computing time on the DFG-funded High Performance Computing (HPC) system CHEOPS as well as for their user support.

\section{Supplementary material}

All code for reproducing the results in this paper is available from the data publication van der Hoog (2016b). To run the model and to perform policy simulations the ETACE Virtual Appliance can be downloaded from this website:

http://www.wiwi.uni-bielefeld.de/lehrbereiche/vwl/etace/Eurace_Unibi/Virtual. Appliance

${ }^{1}$ FLAME website: www.flame.ac.uk

${ }^{2}$ FLAME software: http://github.com/FLAME-HPC 


\section{Introduction}

In many advanced economies small- and medium-sized enterprises (SMEs) account for most of the employment in the economy ${ }^{3}$ Banks and other financial institutions therefore have an important social role to play, to create credit for productive investments, especially in order to support economic development and productive activities by such small businesses.

In the credit view of economic development (Schumpeter, 1934, Ch. 3), Schumpeter makes an important distinction between normal credit and abnormal credit. Normal credit is the primary wave of credit given to the entrepreneur to make investments and to finance innovation. Abnormal credit consists of a secondary wave of credit that finances consumption and speculation into financial assets for which no profits have yet been realized (cf. Bezemer, 2014). The notion of productive credit is also a core argument in favour of Community Development Banks in Minsky et al. (1992). The authors argue along similar lines as Schumpeter, namely that credit should support the local enterprises and communities. These are often small-scale businesses that do not require large loans in the order of millions, but rather small loans in the order of thousands of dollars or euros. The distinction between productive and unproductive credit played an important role in the Japanese Banking Crisis (Werner, 2003, 2005), for which we provide a short overview in Subsection 2.2 below. Investments in unproductive activities could also serve as explanation for the economic stagnation that is hampering economic growth in both the EU and China.

The main theme of this paper can be summarized as "Schumpeter meeting Minsky", namely to study the key role played by productive versus unproductive finance for investments, and how this affects the financial stability of the macroeconomic system as a whole (see also Bank of England, 2016). We consider various proposals to improve the financial stability of the banking system, with a particular focus on mitigation policies and macroprudential regulations that aim to reduce the large debt overhang and the overall economic costs that result from severe downturns. We test the efficacy of such proposals by computational experiments, using a stock-flow consistent agent-based model (SFC-ABM). The model used here was already applied successfully to similar issues related to microprudential regulation in a previous analysis (van der Hoog and Dawid, 2017). This follow-up paper could therefore be seen as an extension of those earlier results, but with a stronger focus on macroprudential regulations.

We consider a financially fragile economy with a high degree of financialization in which (nonfinancial) firms need loans from commercial banks to service their various financial commitments: to produce a final consumption good, to service their outstanding debt, and to make long-term investments. Along the business cycle the economy follows the dynamics of the Minsky base cycle in which firms traverse the various stages of financial fragility, i.e. hedge, speculative and Ponzi finance (cf., Minsky, 1978, 1986, 1992) 4 In the hedge finance stage firms can repay their credit for working capital ('Betriebskredit'), including interest payments, from the current cash flow. In the speculative finance stage the cash flow is sufficient to pay for the debt principle but not for the interest payments and banks are willing to provide roll-over credits in order to prevent their outstanding loans from turning into non-performing loans. In the Ponzi finance

\footnotetext{
${ }^{3}$ According to data from the World Bank Enterprise Surveys reported in Demirguc-Kunt et al. (2015), the median contribution of SMEs to total employment amounts to 66 percent in EU countries, 55 percent in the UK, and 50 percent in the US.

${ }^{4}$ In addition to the base cycle, Minsky also defined a financial super-cycle, in which the stabilizing institutions of the economy are slowly eroding, including the regulations. Minsky called these the "thwarting institutions", since they prevent the financial sector from destabilizing the macroeconomy. Here we only consider the base cycle, keeping the institutions constant over time, but we make comparisons across different institutions by varying the scenarios in the policy analysis.
} 
stage neither principle nor interest payments can be repaid but the banks are still willing to keep firms alive through "extend and pretend" loans, also known as zombie-lending (Caballero et al., 2008). This lending behavior may cause credit bubbles with increasing leverage ratios. Empirical evidence suggests that recessions following such leveraging booms are typically more severe and can be associated to higher economic costs than other recessions (Jordà et al., 2013; Schularick and Taylor, 2012).

In the companion paper we primarily focussed on microprudential regulations, by investigating the micro-level dynamics. We showed that a strengthening of the capital adequacy ratio does not necessarily improve the financial stability of the banking system. In fact, more regulatory capital may lead to an increase in the amplitude of the most severe downturns, while a strengthening of the central bank reserve requirement (more liquidity) leads to a decrease in the amplitude of recessions.

This suggests there exists a U-shaped relationship between the strength of the capital adequacy ratio and the amplitude of recessions, implying that an optimal value at which the amplitude can be minimized is either a very low or very high capital ratio, but not somewhere in the middle. This goes against the common wisdom in the debate about how to reform credit market regulations, in which the main proposals (i.e., Basel III) are for the most part geared towards strengthening the capital requirements.

The reason for this somewhat counter-intuitive result is the absence of strict regulations on the volume of credit, which leads to repeated credit bubbles with each new bubble growing larger than the preceding one. Therefore, a generic result of our analysis seems to be that a more restrictive regulation on the supply of liquidity to firms that are already highly leveraged is a necessary requirement for preventing credit bubbles from occurring again and again.

As a counterpoint to those microprudential results, the current paper offers a macroprudential perspective. We study policy measures that might mitigate the severity and intensity of the economic losses that ensue from such severe downturns. We investigate macroprudential regulations that are aimed at: (i) the prevention and mitigation of credit bubbles, (ii) ensuring macro-financial stability, and (iii) limiting the ability of banks to create unsustainable debt.

We investigate several scenarios varying from banning banks to pay dividends (strengthening their core equity), using non-risk-weighted capital ratios, or cutting off funds to the speculative and Ponzi financed firms. Our results show that the first measure has little effect, while the third has strong positive effects. Cutting off funding to the financially unsound firms results in a strong reduction in the amplitude of recessions and reduces the cumulative economic losses significantly. However, combinations of policy measures do not necessarily increase the effect, pointing to non-linear interactions between the policies.

The contributions of this paper are the following. In Section 2 we review the relevant literature and list the most important empirical stylized facts about the relationship between financial leverage and the business cycle. In Section 3 we set up our methodology such that we can analyse the synthetic data generated by the simulation model using similar methods as those used for empirical data. In Section 4 we describe the agent-based computational model. In Section 5 we consider macroprudential policies such as credit growth limits and loan eligibility criteria, full reserve banking and full equity funding. Finally, Section 6 concludes. 


\section{Relevant literature}

\subsection{Agent-based models and macroprudential regulation}

There is a burgeoning literature on agent-based macroeconomic models and models of financial contagion in credit networks. With the specific focus on credit- and macroprudential regulation in mind, we here only cover the most salient agent-based models that deal directly with such issues.

Particular emphasis on the role of credit markets for aggregate fluctuations is given in Delli Gatti et al. (2003, 2008) and Delli Gatti et al. (2011). An important aspect in their models is that they capture the linkages based on credit relationships between firms and banks, among firms in trade networks, and among banks in inter-bank networks. These properties allow the authors to gain important insights into the relevant mechanisms responsible for financial contagion effects and to explore the implications of different types of banking- and credit market regulations.

Ashraf et al. (2011) explore the effects of different banking regulations, in a model with shop owners where market interactions are governed by search and matching processes. They study the role of banks both in normal times and in times of crises.

Krug et al. (2015) study the impact of the proposed Basel III regulations in an agent-based model with credit networks. They find that the positive joint impact of several microprudential policies to the resilience of the financial system is larger than the sum of the individual effects measured in isolation, demonstrating that the effects of the policies are non-additive. This raises an important point that policies should be considered in unison, and it is important to study whether policies are mutually reinforcing or detracting in their joint effects.

Popoyan et al. (2015) address the impact of strengthening macro prudential credit regulations using a model from the "Keynes meeting Schumpeter" family of models (Dosi et al., 2015). They show that a mixture of macro prudential regulations à la Basel III, in combination with a monetary policy rule that has a combined focus on the output gap, inflation and credit growth, works best to stabilize the banking sector and smooth output fluctuations. They find a similar result as Krug et al. (2015), showing that combinations of policies are not always additive. That is, the inclusion of an additional policy instrument does not always improve the performance of the pre-existing macro prudential regulation.

Another related strand of literature is the Post-Keynesian literature on Stock-Flow Consistent (SFC) models with endogenous money (Lavoie and Godley, 2006, Le Heron and Mouakil, 2008). In this vein, Caiani et al. (2016) have developed an agent-based stock-flow consistent (AB-SFC) model that is proposed as a benchmark model, but in fact is quite similar to ours.

An important distinctive feature of the Eurace@Unibi model with respect to the models mentioned above is that it provides an all-encompassing macroeconomic framework for capturing the feedback effects between different markets and has been calibrated to reproduce empirical stylized facts at different levels of aggregation (see Dawid et al. 2017). Another advantage of using the Eurace@Unibi framework is that it has already been applied to policy analyses in several other domains, which not only reinforces the confidence that it is a suitable tool for policy evaluation, but also allows us to compare the implications of different policies from various domains and to study their interactions.

Whereas the cited papers usually restrict attention to a single policy domain, or aggregate the balance sheets of individual agents into sectoral balance sheets by assuming a single bank or a single household to supply labour, or restrict attention to the firm's financial position, in the Eurace@Unibi model we can consider all agents and market interactions simultaneously. Thereby not neglecting the possibility of interactions between policies on the credit market with 
policies on the other markets. Although the specific focus of our analysis is on the implications of credit market regulations, it still seems necessary to take into account such feedback effects on the consumption, capital goods and labour markets.

\subsection{The Japanese Banking Crisis and Zombie Lending}

Over the course of the Japanese Banking Crisis in the 1990s many Japanese banks were rolling over the debt of firms that should have already been declared insolvent, in order to avoid losses to its own balance sheet due to non-performing loans (see Werner, 2003, 2005; Miyajima and Yafeh, 2007 for in-depth analyses). The type of unproductive firms that are kept "artificially alive" by the banks has been termed "zombie firms" by Caballero et al. (2008), and the practice of rolling-over their debt indefinitely is called "ever-greening" or "zombie-lending". Our baseline scenario fits the story of zombie firms being supported by ever-greening during a downturn.

Recent studies of the Japanese banking crisis have attempted to characterize what kind of firms are most sensitive to a lack of availability of bank credit. Mostly these are firms with high levels of leverage, large bank debt, and low profitability. Small firms are usually more affected since those have more limited access to financial (i.e. bond) markets. A second class of firms highly sensitive to disruptions in the supply of credit are the zombie firms, consisting of relatively large firms with relatively low performance and whose leverage increased consistently during the 1990s. The process of 'zombie-lending' that banks were using to support firms for their own survival is a feasible explanation for sluggish growth and a highly leveraged real sector, also in our simulation model.

For the European banking crisis, Acharya et al. (2016) report on the effects of the ECB's Outright Monetary Transactions (OMT) Program, which led to a recapitalization of undercapitalized banks in the European periphery countries (i.e, the GIIPS countries Greece, Ireland, Italy, Portugal and Spain). The OMT Program allows these banks to sell their holdings of sovereign bonds to the ECB in return for cash reserves. This additional liquidity was predominantly used to extend already existing credit-lines of the banks' existing borrowers, rather than for the creation of new loans to new borrowers. The authors identify the zombie-lending phenomenon as a severe form of credit misallocation leading to credit congestion that is severely hampering real economic growth. In particular, they document that in industries with a large presence of zombie firms there is a negative crowding-out effect on the credit market of the high-quality, non-zombie firms.

The continued financing of otherwise insolvent firms by rolling-over their debt and taking on more leverage causes two problems. First, it prevents a deleveraging and subsequent restructuring of the financially unsound firms. Second, the unhealthy and highly risky borrowers cause a congestion on the credit, goods and labour markets. On the credit market, they take out liquidity that cannot be used to fund smaller, more productive firms that are financially healthier. This inefficient allocation of funds prevents the small firms from growing. Also, the unsound firms maintain a large capital stock by investments that are purely debt financed, whereas the healthy firms do not invest since they are facing distorted competition on the product market from the zombie firms that are producing with "unfairly obtained" capital ("unfair" in the sense that it resulted from uncritical risk-assessments by the banks). On the labour market the unhealthy firms are hoarding productive workers that could otherwise be hired by the healthy firms.

There is ample anecdotal evidence that a similar phenomenon as in Japan's 1990s is currently at work in China and is a prime cause of the stagnating growth of the Chinese economy. Schuman (2015) describes how Chinese cement factories do not file for bankruptcy, in order to prevent 
having to pay severance payments to their idle employees. These employees are often highly qualified engineers who do not want to quit their job out of a fear of losing their claims to unemployment benefits and severance pay. These highly skilled people cannot be hired by other firms. Thus, the small and more productive firms are thwarted from getting a highly qualified workforce, from investing and augmenting their capital stock, and from getting loans from the banks. Hence they remain small, and cannot hire the workers they need to produce and get the economy to grow again.

There is a responsibility for monetary policy here as well. For the banks to be able to prop up the zombie firms a sufficient amount of liquidity is needed. If the monetary policy of the Central Bank is to act as a lender of last resort and therefore to adopt a fully accommodating monetary policy, it will provide the banks with all the liquidity required, and as a consequence the outcome described above would be possible. At least, it would be consistent with the observation that: (i) more loans are allocated to the financially weakest firms; (ii) these firms pay lower than average interest rates to entice them into taking on more debt; and (iii) by propping up such fragile firms an early deleveraging is avoided, making it easier for the banks to pretend everything is fine. As a result, both the real sector and the banking sector turn out to be more fragile, and the average equity to asset ratios are lower in both sectors, since a deleveraging recession, either gradual or sudden, has not taken place.

\subsection{Financial intermediation and economic development}

The literature on financial deepening and economic development (McKinnon, 1973; Shaw, 1973 ; Arestis and Demetriades, 1997) studies the role of financial intermediaries in the process of economic development. This literature has featured long-standing debates on the role of financial intermediation, financial liberalization, the expansion of credit, and their effects on investments and economic growth. A survey is provided by Ang (2008) . $^{5}$ A general conclusion from this 'classical' literature is that an expansion in the availability of credit, or an increase in financial intermediation, typically has positive long-run growth effects due to its stimulating effect on investments. In this view, the banks are merely seen as the providers of liquidity, functioning as conduits through which the deposits from savers are intermediated towards the investments of producers. In this interpretation, more credit is always positively associated to more economic development and hence more credit growth is preferred to less.

In this older strand of the literature, financial development is typically measured by the credit to GDP ratio, while financial depth is measured by the broad money (M2) to GDP ratio. One empirical stylized fact is that an increase in financial depth from 20 to 60 percent would increase output growth by 1 percent per year (Terrones, 2004). This depends on whether the increased availability of credit contributes to permanent financial deepening, and on whether the quality of financial deepening acquired through a sharp increase in credit resembles the deepening achieved through gradual credit growth.

However, since the Latin American Debt Crisis in the 1980s and the Japanese Banking Crisis in the 1990s the literature on financial deepening has shifted its focus somewhat and since then also considers the negative side-effects of an increase in financial fragility. Empirical studies since the 2000s now also feature the stylized fact that negative short-run effects on growth are greater if the frequency of crises is higher or if the financial volatility is higher (Loayza and Rancière, 2006). It is therefore of interest to policy makers and regulatory authorities to closely

\footnotetext{
${ }^{5}$ The literature features models linking financial intermediaries and growth in endogenous growth models (Greenwood and Jovanovic, 1990, Bencivenga and Smith, 1991, 1993, Boyd and Smith, 1998) and models of financial fragility and contagion through interbank markets (Bernanke and Gertler, 1989, Goodhart et al. 2005).
} 
monitor the formation of credit bubbles and to restrict any excessive risk-taking by the financial sector.

Loayza and Rancière (2006) point to two effects of financial liberalization and credit expansion on investment and growth. On the short-run, a destabilizing effect is that over-lending can occur due to a limited ability of banks to monitor and discriminate investment projects during the boom phase of the cycle. The expansion of credit may lead to a systemic banking crisis, possibly triggering a recession. Increases in financial volatility lead to short-run instability, and a growth slowdown. However, on the long run, the greater availability of credit (financial depth) has a positive effect on per capita GDP growth. This is known as the growth enhancing effect of financial development (King and Levine (1993); Levine et al. (2000)).

Rancière et al. (2008) also find evidence for a trade-off between economic growth and stability, stating that "there is a positive correlation between the number of years a country has undergone a credit boom and the cumulative real GDP per capita growth achieved since 1970. However, this relationship seems to flatten when credit booms become too frequent, and because countries with more credit booms also experience more crises (on average), there seems to be a trade-off between macroeconomic performance (growth) and stability."

This linkage between the financial cycle and the business cycle has since been at the forefront of empirical macroeconomic research, and a large literature on empirical evidence of the role of financial leverage in the business cycle has ensued.

\subsection{Financial leverage and the business cycle}

A long-standing view in the literature is that, with regard to asset price bubbles, it would be easier and less costly to deal with the aftermath of a bust, rather than trying to prevent a bubble from occurring in the first place. This is related to the belief that it is difficult to detect beforehand whether a boom is 'healthy' or 'unhealthy', and that it would be much more costly to restrain the credit growth rather than "cleaning up the mess after the crash" (Dell'Ariccia et al., 2014).

On the other hand, after the financial crisis of 2008 there has also been some debate on integrating monetary policy and macroprudential regulation (see Canuto and Cavallari, 2013): "Prior to the crisis, the prevailing opinion became that the best approach would be to use monetary policy only to 'clean up' the financial mess after a bubble bursts. More recently, an intermediary position gained prominence: the 'mop-up-afterwards' approach would be appropriate for equity bubbles not fuelled by over-borrowing, whereas the central bank should try to limit credit-based bubbles - though probably combining micro-regulatory instruments and interest rates. This view may eventually become the new consensus on how to deal with asset price bubbles; indeed, Bernanke (2010) came close to endorsing it."

As part of this new, broad research agenda in empirical macroeconomics to better understand the role of financial factors in the business cycle, and how financial fragility affects macroeconomic outcomes, Schularick and Taylor (2012) study a long-run dataset covering 14 advanced economies over the period 1870-2007. Their aim is to systematically re-examine the evidence on the causes and consequences of financial fragility. They find that recessions following an expansionary phase with excessive leveraging are typically more severe than 'normal' recessions and are associated with higher economic costs. In an extensive econometric follow-up study, Jordà et al. (2013) uncover several empirical regularities (see Section 2.5).

In a similar empirical study, Claessens et al. (2012) try to uncover the strong interrelationships between business cycles and financial cycles. Using a dataset covering 44 countries (21 advanced OECD and 23 emerging market economies) over the period 1960-2007, they identify 
200 episodes of business cycles and 700 episodes of financial cycles. They use data at quarterly frequency whereas most other studies use data at annual frequency, allowing for a more granular analysis. Their main finding is that credit- and housing markets are important for understanding fluctuations in the real economy since recoveries that coincide with a credit- or housing boom turn out to be much stronger, while if the preceding recession was associated to a credit or housing bust then the subsequent recovery often turns out to be much weaker.

A recurring theme in all these empirical studies seems to be that higher financial leverage raises the vulnerability of an economy to shocks, and leverage functions as a propagation mechanism for other destabilizing effects such as the financial accelerator (Bernanke and Gertler, 1990). If left unattended, such vulnerable economies may enter into a balance sheet recession (Koo, 2009) with the ensuing damaging effects of a debt deflation (Fisher, 1933). Or, possibly even worse, it may result in long periods of secular stagnation (Summers, 2014).

\subsection{An overview of empirical facts linking leverage and the business cycle}

Recent studies have uncovered many new empirical facts about the relationship between business cycles and financial leverage. Below we distinguish between general historical facts, facts about expansions, and facts about recessions ${ }^{6}$

Historical facts, based on 140 years (1870-2007) of business cycle history in 14 advanced economies (all from JST):

(1) A close relationship exists between the build-up of debt and financial leverage during the expansionary phase of the business cycle and the severity of the subsequent recession.

(2) A stronger increase in financial leverage, as measured by the rate of growth of bank credit to GDP during the boom, tends to be associated with deeper subsequent downturns.

(3) The relationship tends to be stronger:

(a) when the recession coincides with a systemic financial crisis;

(b) in economies with larger financial sectors (more 'financialized' economies).

(4) (a) the duration of expansions has increased over time (from 2.7 years before WWI to 9 years post-Bretton Woods).

(b) the rate of economic growth during expansions has decreased (from 5 percent before WWI to 2.4 percent in more recent times), but the credit-intensity (financial leverage) has increased.7

(c) the amplitude of recessions has declined.

(d) the duration of recessions has remained about the same over this period of time.

Empirical facts about expansions, in relation to their credit-intensity:

\footnotetext{
${ }^{6}$ We use some abbreviations in the overview: JST stands for Jordà et al. (2013), DILT stands for Dell'Ariccia et al. (2014), CKT stands for Claessens et al. (2012), RR stands for Reinhart and Rogoff (2009), CS stands for Cerra and Saxena (2008).

${ }^{7}$ This could be a sign that finance is being used for more non-productive investment, which is defined roughly as expenditures that do not contribute to a potential expansion of the production capacity of the economy. But no empirical data exists to measure how much of total finance is used for non-productive investment, cf. Bank of England (2016).
} 
(5) Duration: In periods with high leverage, expansions last almost an extra year (9.7 versus 8.9 years for low-leverage expansions) (JST).

(6) Growth: The per year economic growth rate during expansions with high leverage is larger than during low-leverage expansions (3.4 versus 2.7 percent in low-leveraged expansions) $(\mathrm{JST}){ }^{8}$

(7) Amplitude: The amplitude of high-leverage expansions is larger than of low-leverage expansions (38 versus 28 percent in low-leverage expansions) (JST).

(8) Duration: The median boom lasts three years, with the credit-to-GDP ratio growing at about 13 percent per year, or about five times its median growth in non-boom years (DILT).

(9) Recoveries that coincide with booms in the credit and housing markets are stronger, while if the prior recessions are associated with housing busts, these are often weaker (CKT).

Empirical facts about recessions, after a financial crisis:

(10) Amplitude: After a financial crisis, output declines by about 7.5 percent of GDP in 10 years (JST).

(11) Duration: Recessions after a financial crisis last on average about four years (RR).

(12) The historical average of the decline in output is approximately 9 percent, while the unemployment rate rises an average about 7 percentage points during the downturn (RR).

(13) Recessions accompanied by house price busts tend to be longer and substantially deeper than normal (CKT).

Empirical facts about the relationship between the credit-intensity of the prior boom phase and the economic growth rate in the subsequent recession (all from JST):

(14) Recessions after a financial crisis tend to be associated with sharp slowdowns in credit growth rates and investments. This effect gets amplified if leveraging during the preceding expansion was larger.9

(15) A higher credit-intensity during the boom phase is associated with slower growth of real GDP per capita in the subsequent recession phase (a coefficient of -0.63 percent, significant at the 1 percent level, is found; this means that a one standard deviation increase in the credit-intensity corresponds to an extra $0.63 \%$ decrease in real GDP per capita) .

(16) Excess credit is a problem in all business cycles not just those that end with a financial crisis.

\footnotetext{
${ }^{8}$ This could be a sign of debt-led growth.

${ }^{9} \mathrm{~A}$ possible explanation for the observation that highly leveraged expansions are typically followed by a credit crunch is that banks have to rebuild their balance sheets, so they even restrict credit supply to businesses that have real investment opportunities. Such recoveries with weak credit supply are also known as "creditless recoveries" (Abiad et al. 2011). This credit supply-oriented explanation should be complemented by a credit demand-focussed explanation that households and businesses are also rebuilding their balance sheets and are deleveraging. In this explanation it is weak credit demand, rather than weak credit supply, that explains the slowdown in credit growth after a financial crisis.
} 
(17) The duration of the subsequent recession is not significantly affected by the credit-intensity of the prior boom phase.

(18) Higher credit-intensity of the prior boom is associated with a greater amplitude of the subsequent recession (a coefficient of -1.4 percent, significant at the 1 percent level, is found; this means that a one standard deviation increase in the credit-intensity corresponds to an extra $1.4 \%$ decrease in real GDP per capita) ${ }^{10}$

(19) In the aftermath of credit-fuelled expansions that end in a systemic financial crisis, downward pressures on inflation are pronounced and long-lasting 11

\section{Methodology}

\subsection{Simulation methodology}

From a mathematical point of view, an agent-based model (ABM) is a multivariate, non-linear stochastic process. In most cases, and for all intents and purposes, an ABM can be represented as a finite-order Markov process. However, some caveats should be kept in mind.

Ordinary Markov Chains (first-order Markov processes) possess the Markov property, i.e. they are memoryless, which implies that the transition probabilities from the current state to the next states only depends on the current state and not on the sequence of states preceding it. This means that history does not matter, and we can start from any state as the initial state and the dynamics will evolve in exactly the same way as when we would have had a history that ended in that "initial" state and we observed how the system evolved forward in time from there.

However, most agent-based models contain decisions of agents that depend on history and the dynamics shows long-term time dependencies that result in hysteresis, a memory property of dynamical processes. In such cases the state transitions are not memoryless, so such processes do not satisfy the (first-order) Markov property. Mathematically, these can be represented as $N^{t h}$-order Markov processes, that is, as processes in which the state transition probabilities depend on the previous $\mathrm{N}$ states of the system.

From a computational point of view, such processes can be rigorously analysed using finite state machines (FSM). To apply the state machine methodology to agent-based models, however, the implementation should be based on a mathematical modelling formalism for multi-agent systems (see Holcombe, 1988; Kehris et al., 2000, 2005). The Flexible Large-scale Agent Modelling Environment (FLAME ${ }^{12}$ ) is based on such a formal model of computation, in which agents are modelled as Communicating Stream X-Machines (CSX, see Holcombe and Ipate, 1998: Balanescu et al., 1999; Ipate, 2004). In contrast to FSMs, CSX-Machines contain memory variables such that the state transitions can depend on the memory of the previous state, making the state transitions history dependent. The state transitions can also induce a modification of the memory variables. For a general description of FLAME, see Coakley et al. (2006). For comparisons to other (agent-based) simulation platforms such as Mason and Repast, see Coakley et al. (2012b).

\footnotetext{
${ }^{10}$ These results imply that the impact of the credit-intensity during the boom phase works through the amplitude rather than through the duration of the recession. The average duration of recessions is insensitive to the leverage, while the amplitude is affected by the credit-intensity of the prior boom.

${ }^{11}$ This result indicates that there should be no reason to fear any inflationary pressures from an expansionary monetary policy after a financial crisis episode.

${ }^{12}$ See the FLAME website http://www.flame.ac.uk/ for downloads.
} 


\subsection{Data analysis methodology}

The algorithm used to obtain the results for this paper is based on well-established methods from the empirical literature to study macroeconomic time series data and business cycle dating 13

We adopt a similar methodology to time series data analysis as in Claessens et al. (2012). The only difference is that we use synthetic data generated by our simulation model, while they use empirical data. The analysis is based on the detection of peak and trough dates in the time series of output, followed by a conversion into recession and expansion periods according to the standard definitions.

In the U.S., the NBER defines an economic recession as: "a significant decline in economic activity spread across the economy, lasting more than a few months, normally visible in real GDP, real income, employment, industrial production, and wholesale-retail sales." (National Bureau of Economic Research, 2007) In the EU, however, recessions are defined in a more technical manner as: "two consecutive quarters of negative economic growth, as measured by the seasonal adjusted quarter-on-quarter figures for real GDP." (HM Treasury, 2010)

In our business cycle dating algorithm, we do not refer to real GDP since that requires a deflator. Instead we use the quarter-on-quarter growth rates of the actual units of output that have been produced during one quarter. Since we are particularly interested in the effects of severe downturns, we would like to measure the amplitudes of recessions. In order to detect such amplitudes, a recession has to be a well-defined statistical object, and an algorithm is needed to detect when a recession starts and when it ends. For the business cycle we use the term expansion to indicate an increase, and recession for a decrease in output. For the credit (financial) cycle the corresponding terms are upturn for an increase, and downturn for a decrease in the total private sector debt, measured in terms of the total firm credit volume.

After having determined all start and end dates of recessions, recoveries and expansions across a time series, we collect all such statistical objects across an ensemble of Monte Carlo replications. That is, for each parameter setting we perform multiple runs of the simulation model with different seeds for the random number generator 14 This ensemble of all start and end dates is fed into the recession analysis algorithm for further analysis. It thus contains the distribution of all recessions, recoveries and expansions, across all Monte Carlo replications, and for multiple parameter settings.

As in Claessens et al. (2012), we proceed by computing various statistical measures along each recession, recovery and expansion: the amplitude (depth), the duration (time), the slope (amplitude per unit of time), and an aggregated approximation of the leverage ratio of all firms (total firm debt divided by total firm equity). For the recessions we also measure the cumulative economic costs of foregone production, which is given by the total number of units that would have been produced if there would not have been a recession. This is measured from the level of output at the start of the recession, along the entire duration of the recession.

Finally, a statistical analysis of these measurements is made and we show box plots of the distributions over all recessions observed across an ensemble of simulation runs, and for the various policy scenarios under consideration. This allows us to judge the economic costs involved when comparing various policy proposals for micro- and macroprudential regulations.

\footnotetext{
${ }^{13}$ The classic reference to business cycle dating algorithms is the original Bry-Boschan (BB) algorithm developed by Bry and Boschan (1971), and the quarterly Bry-Boschan (BBQ) algorithm proposed by Harding and Pagan (2002). For this paper, we have implemented our own version of the BBQ algorithm in the software package R. More details can be found in Appendix A The code is included in the source code that is available from our website.

${ }^{14}$ The typical number of replications is 100 runs per parameter setting. The random number seeds are themselves randomly drawn from a uniform distribution, and then stored.
} 


\section{Model summary}

Since in this paper we primarily focus on macroprudential regulation of the banking sector, and due to space constraints, we do not want to burden the text with a full model description. This section therefore provides a quick overview of the essential model ingredients that are directly relevant to the analysis 15 For more extensive specifications of the labour market, consumption goods market, and investment goods market, detailed model descriptions can be found in Dawid et al. (2016). For an overview of empirical stylized facts that can be reproduced using the Eurace@Unibi model, we refer to Dawid et al. (2017).

\subsection{Firm sequence of activities}

Each firm proceeds through the following sequence of economic activities:

1. On the firm's idiosyncratic activation day the firm starts its production cycle with production planning. The production plan consists of planned output based on historical observations and the results of market research. Based on the production plan the firm determines its planned input demand for capital and labour.

2. Financial management of the firm. The firm computes the costs of production and the costs for financing its commitments. If the internal resources are insufficient the firm tries to finance externally by requesting credit.

3. Credit market with direct firm bank linkages opens. The banks create loans by servicing the credit requests on a daily basis, ranking the requests on their credit risk in ascending order. The bank decides on the credit conditions for the applying firm (interest rate and amount of credit provided) depending on the firm's financial situation (debt to equity ratio). If the credit request is refused, or not fully granted, the firm has to reduce its planned production quantity.

4. Bankruptcy of two types could occur. If the firm is credit constrained to such an extent that it is not able to pay the financial commitments it becomes illiquid and illiquidity bankruptcy is declared. If at the end of the production cycle revenues are so low that the firm has negative net worth, the firm is insolvent and insolvency bankruptcy is declared. In both cases it goes out of business, stops all productive activities and all employees loose their jobs. The firm writes down a fraction of its debt with all banks with which it has a loan and stays idle for a certain period before it becomes active again.

5. Investment goods market opens. Depending on the amount of financing secured, the firm makes its investment decision, consisting of a quality and quantity choice.

A default feature of the Eurace@Unibi model is that technological progress is modelled by introducing a new vintage of capital with a higher quality whenever there is a successful innovation. This new vintage has a higher productivity, but is also more expensive. However, old vintages remain available and continue to be produced. Therefore at each point in time there is a supply of vertically differentiated investment goods offered at differentiated prices. This is referred to as a vintage capital structure.

Concerning the investment decision, the "vintage choice" is related to the quality of the investment goods. That is, the consumption goods producer chooses which productivity

\footnotetext{
${ }^{15}$ Below we re-use some material that was previously developed in van der Hoog and Dawid (2017).
} 
level to invest in. The other part of the investment decision consists of how much to buy. This implies that the capital stock inside each firm consists of a heterogeneous ensemble of different vintages. For the production function we consider the average productivity of this heterogeneous capital stock, in complementarity with the average productivity of the work force, to determine the actual output produced.

6. A decentralized labour market opens where firms with open vacancies are matched to unemployed households. The matching is based on the firm's wage offer and the employee's skill level and reservation wage. The specific skill level of the prospective employees is chosen such that it is compatible with the capital stock, since the two average productivity levels of the inputs labour and capital are complementary in the Leontief production function that is being used in the Eurace@Unibi model.

7. Production takes place on the firm's activation day. After production is completed, the output is distributed to local malls. Firms offer goods at posted prices with price revisions occurring once a year. Firms estimate their elasticity of demand based on simulated purchase surveys on a test market. Using this estimate and information about their production costs they determine their expected future discounted profits over their planning horizon for different choices of price and quantity. Price and quantity are then chosen such that this expected profit is maximized. Prices will be heterogeneous across firms due differences in cost structures, and because the simulated purchase surveys take into account the current prices of all competitors in the market, which implies that the estimation of the elasticity of demand that an individual firm faces differs between the different firms in the market.

8. At the end of the production cycle the firm computes its revenues, and updates its income statement and balance sheet. It pays taxes, dividends, interests and debt installments. It checks if net worth is negative and if so, declares insolvency. Otherwise it continues with the next production cycle.

\subsection{Financial management}

To model the balance of power between the firm's creditors, shareholders and management, we consider a dichotomy by distinguishing between the firm's past and present financial commitments. Taxes and debt repayments (principle and interests) are commitments from the past, so these have to be financed at the start of the next production cycle, or else the firm cannot continue its normal operations. The production costs for the new production cycle (labour wages and planned investments) are financial commitments in the firm's present. We first combine all financial commitments and try to finance these simultaneously on the credit market. If we would first pay taxes and dividends out of the current cash flow, this could hamper debt repayment, or new production. By combining all prior financial commitments with the financial needs for the new production cycle, a priori we do not prioritize any commitment over any other, past or future.

The dividend payout is a special case that could be considered as a fixed commitment from the past, to be financed out of the current cash flow. However, since the dividend payout could also be made a function of past performance over some longer time horizon, it could occur that the total dividend payout exceeds current available funds. Furthermore, empirical evidence points out that firms sometimes even obtain new debt to perform share repurchases or dividend payouts in extent of their total net income (cf. Lazonick, 2014). Another argument against 
considering dividends as a fixed commitment is that cutting dividends is the cheapest form of funding available. Therefore we have included the dividend payout in the present commitments as a current management decision after the realized profits are known. Since management wants the firm to be productive, we prioritize real production over shareholder remuneration, and dividends are not automatically positive when profits are positive.

On the other hand, the creditors and the Government do have some priority over the shareholders. If the firm is experiencing any credit rationing we therefore proceed by setting dividends to zero. The firm also re-plans its production by downscaling planed output levels such that the new plan fits the actual funds available. If it lacks the funds to finance any production at all, it also sets the output level to zero. So implicitly we are giving the highest priority to debt repayment and taxes, followed by real production, and finally to dividends. Hence, if the firm is in a financial crisis the management chooses to keep the business alive, rather than rewarding the shareholders.

\subsection{Profits}

The realized profit of a consumption goods producer equals the sales revenues plus interest received on bank deposits minus the production costs (fixed and variable costs). Hence, $\pi_{i, t}$ is determined at the end of month $t$ as:

$$
\begin{aligned}
\pi_{i, t} \quad=R_{i, t}+r^{b} M_{i, t}-\left(C_{i, t}^{\text {Fix }}+C_{i, t}^{\text {Var }}\right) \\
=R_{i, t}+r^{b} M_{i, t}-\left(\sum_{l=1}^{T^{L}} \frac{p_{t-l}^{i n v} \cdot I_{t-l}}{T^{L}}+\sum_{l=0}^{T^{L}} r_{i, t-l}^{b} L_{i, t-l}^{b}\right)-\left(W_{i, t}+\frac{p_{t}^{i n v} \cdot I_{t}}{T^{L}}\right) .
\end{aligned}
$$

The fixed costs $C_{i, t}^{\text {Fix }}$ consist of the fixed capital expenditures over the previous periods $\left(t-T^{L}, \ldots, t-1\right)$ and the interest due on loan contracts over the periods $\left(t-T^{L}, \ldots, t\right)$ that includes the loan obtained at the start of this period $t$. Here $T^{L}$ represents the duration of a loan which typically is multiple months, $T^{L}=18$. Note that the amortization period of the loan is set equal to the accounting period of the fixed capital expenditures. This implies that the economic profit is equal to the accounting profit ${ }^{16}$ The variable costs $C_{i, t}^{V a r}$ consist of the wage bill $W_{i, t}$ and the fraction of total investments that are accounted for in the current month.

\subsection{Dividend payout policy}

In a survey on dividend payout policies among real-world Chief Financial Officers (CFOs), Brav et al. (2005) find that most CFOs are rather conservative with increasing dividends. A possible justification seems to be that a downward adjustment at a later stage might have negative consequences for the firm's asset price. An increase in dividends therefore mostly occurs if there has been a structural improvement in the firm's financial status which is expected to continue in the near future. In our model, this structural improvement is proxied by considering the monthly dividend payment as a moving average of previous profits, in order to prevent too much volatility in the dividend payout in line with empirical evidence. It also implies that the current profits may not suffice to finance the current dividend payout, and the firm possibly

\footnotetext{
${ }^{16}$ In other words, the investments in previous periods are spread out across multiple periods as calculatory costs, in order to prevent the expenditures for investments to have a large impact on profits in those months. For convenience, the time over which the calculatory costs are written off is equal to the time over which the loan is paid off.
} 
needs to finance its dividends by new funds. We define average net earnings (after-tax profits) over the last $n$ months as $\left\langle\pi_{i}\right\rangle_{n}=\frac{1}{n} \sum_{s=0}^{n-1} \pi_{i, t-s}$.

The planned dividend payout in the current month is defined using a moving average of previous profits and the constant dividend rate $d$ (by default, $d=70$ percent):

$$
\operatorname{Div}_{i, t}=d \cdot\left\langle\pi_{i}\right\rangle_{4}
$$

However, note that this planned dividend payout is conditional on the availability of funds, and can be cut if the firm is credit rationed.

\subsection{Firm credit demand}

The planned total expenditures at the start of the new production period $t+1$ consist of the anticipated wage bill and planned total investments, previous period's taxes, the planned dividend payout, and the fixed debt installments and interest payments:

$$
\begin{aligned}
E_{i, t+1} & =W_{i, t+1}+p_{i, t+1}^{i n v} \cdot I_{i, t+1}+\tau \max \left[0, \pi_{i, t}\right]+\operatorname{Div}_{i, t} \\
& +\sum_{l=0}^{T^{L}} \frac{L_{i, t-l}}{T^{L}}+\sum_{l=0}^{T^{L}} r_{i, t-l}^{b} \cdot L_{i, t-l} .
\end{aligned}
$$

The last two terms represent debt installments and interest payments on old loan contracts for the previous periods $\left(t-T^{L}, \ldots, t\right)$ that now need to be serviced. Note that by using this formulation, we allow the firm to obtain a new loan to pay for its taxes and dividends of the previous period, as the empirical evidence in Lazonick (2014) points out.

The demand for bank loans is the remaining part of the total liquidity needs that cannot be financed internally from the payment account (all variables below are determined at the start of period $t+1)$ :

$$
L_{i, t+1}=\max \left[0, E_{i, t+1}-M_{i, t+1}\right] .
$$

Firms shop around for credit conditions (the interest rates are variable, the debt repayment period is fixed to 18 months). the firms request the same amount of credit from a random subset of banks (by default, we let a firm select 2 out of 20 banks at random). Given the credit conditions, the firm then selects the bank with the lowest interest rate offer ${ }^{17}$ Thus, this generates an endogenous network of random credit relationships between banks and firms with some persistence due to the long debt repayment period.

\subsection{Debt deleveraging and restructuring}

Debt deleveraging is modelled by re-scaling the total debt. To make it easier for re-entering firms to obtain new loans we should improve their debt-equity ratio and lower their risk of default. This makes it more likely for a bank to accept any future loan requests from such a debt-restructured firm.

Due to the stock-flow consistency, any rescaling of debt by the firm will improve the firm's balance sheet at the expense of the balance sheets of its creditors, i.e. the banks. If the firm's

\footnotetext{
${ }^{17}$ If there is credit rationing firms do not care about the volume of credit obtained, so the choice of bank is a purely price-driven decision. An alternative modelling choice would be to consider a volume-based decision by the firm. I thank one of the referees for this remark.
} 
equity increases, then the banks' equity necessarily declines by the same amount, due to the write-off of bad debts 18

In fact, bankrupt firms never exit the economy, but instead go out of business for one year, and then we check whether the firm can resurface with positive equity. During the idle year, the firm does several things to restructure:

1. The firm writes down all of its loans by a certain percentage (but not a total write-off), such that its new target debt equals a fraction of its total asset value (this is a parameter, typically the target debt is set to $30 \%$ of the total asset value). Since it depends on the current total asset value, the write-off percentage is determined dynamically during the simulation, so it varies from case to case. This ensures equity is positive again, since the target debt is below the total asset value. We assume the firm is always successful in writing down its loans, so there is no bargaining power on the part of the bank.

2. The firm freezes all debt principle and interest payments on the remaining outstanding debt during the idle year. This is done in order to facilitate the firm's resurfacing after one year. But after the resurfacing, the firm has to resume paying off the remainder of its old loans.

3. The firm retains its capital stock and money on its bank account. The capital stock does not depreciate when it is not being used, and the bank account yields some minor interest from the bank.

If equity was negative at the start of the debt restructuring year, the firm is technically insolvent and does a debt-to-equity transformation by writing down each loan with each bank that it has a credit relationship with. So in case of insolvency, the new target debt $D_{i, t}^{*}$ is set lower than the total asset value $A$. The debt rescaling parameter $\varphi$ is assumed to be constant across all firms and over time:

$$
D_{i, t}^{*}=\varphi A_{i, t} \quad \text { with } \quad 0 \leq \varphi \leq 1 .
$$

After the debt restructuring, the equity of the restructured firm is now positive, $E_{i, t}^{*}=(1-$ $\varphi) A_{i, t}>0$. The debt/equity-ratio after rescaling is given by the constant: $D_{i, t}^{*} / E_{i, t}^{*}=\varphi /(1-\varphi)$.

However, in case of an illiquidity bankruptcy (in contrast to the insolvency bankruptcy), we should not rescale the debt as a percentage of the total asset value since that might lead to a higher debt than the original debt level since $D_{i, t}$ is already lower then $A_{i, t}$ and equity is still positive. The firm does not need to renegotiate its debt per se in this case. However, since the firm is unable to pay its financial commitments it should raise new funds. It could do so either on the credit market or in the stock market by means of issuing new shares, but since we have precluded firms from issuing new shares (for reasons of simplicity) we also allow the illiquid firms to write down part of their debt. So in the illiquidity case we rescale the new target debt to a proportion of the old debt, again by writing down all loans uniformly, resulting in a new total debt given by:

$$
D_{i, t}^{*}=\varphi D_{i, t} \quad \text { with } \quad 0 \leq \varphi \leq 1 .
$$

\footnotetext{
${ }^{18}$ Note however that we do not yet have a clear separation between the regulatory capital (equity) and a loan loss reserve on the balance sheet of the bank. Normally, whenever a loan is issued, the bank makes a loan loss provision (a flow) by transferring equity to the loan loss reserve (a stock). This is a liability transformation. Any bad debt is written off from the loan loss reserve and does not affect the equity directly. However, if the write-off is substantial and exceeds the loan loss reserve, then this starts to eat into the bank's equity nonetheless.
} 
This has the positive effect that it improves the firm's financial position, with higher equity after the debt restructuring year. New equity is given by $E_{i, t}^{*}=A_{i, t}-\varphi D_{i, t}>E_{i, t}$ and a new debt-to-equity-ratio is $D_{i, t}^{*} / E_{i, t}^{*}=\varphi D_{i, t} /\left(A_{i, t}-\varphi D_{i, t}\right)<D_{i, t} / E_{i, t}$.

Setting a lower value for the debt/equity-ratio will improve the firm's chances of obtaining new credit and possibly resolve its illiquidity status. For this the debt rescaling parameter $\varphi$ must be set to low values $(\varphi \leq 0.5)$ such that the new target debt-to-equity ratio is much smaller than the original debt-to-equity ratio. If after the debt restructuring year and the new credit market interaction the firm is once again credit rationed, and remains in the illiquid state, it will remain out of business and could stay there indefinitely.

\subsection{Banking sector}

\subsubsection{Bank accounting}

Bank reserves fluctuate with deposits and withdrawals, interest payments, and finally also with taxes and dividends. The net profits (or losses) after taxes and dividends are added to the reserves and held at the Central Bank. Profits $\pi_{t}^{b}$ at the end of month $t$ are determined by:

$$
\begin{aligned}
\pi_{t}^{b} & =\sum_{i} r_{i}^{b} L_{i t}^{b}-r^{b}\left(\sum_{h} M_{h t}^{b}+\sum_{i} M_{i t}^{b}\right)+r^{c}\left(M_{t}^{b}-D_{t}^{b}\right), \\
M_{t+1}^{b} & =M_{t}^{b}+\Delta M_{h t}^{b}+\Delta M_{i t}^{b}+(1-\tau) \max \left[0, \pi_{t}^{b}\right]-d^{b}(1-\tau) \max \left[0, \pi_{t}^{b}\right] .
\end{aligned}
$$

The bank's profits consist of the margin between interests on loans and interests on deposits, plus (minus) any interest paid by (to) the Central Bank on overnight reserves (reserve debt). In case of positive profits, the bank pays taxes and dividends at rates $\tau$ and $d^{b}$, resp. The net mutations of the demand deposit accounts are given by $\Delta M_{h, t}^{b}=M_{h, t}^{b}-M_{h, t-1}^{b}$ and $\Delta M_{i t}^{b}=M_{i, t}^{b}-M_{i, t-1}^{b}$, resp.

\subsubsection{Bank credit supply and risk-taking behaviour}

The bank's ability to provide credit is restricted by a Capital Adequacy Requirement (CAR) and the Reserve Requirement Ratio (RRR). The bank's risk-taking behaviour depends on its current level of exposure to default risk and the capital requirement.

Firms select banks at random in each production period, so the credit market can be viewed as a random matching process. The bank records several characteristics of the applying firms: total debt, size of credit requested, firm equity, and additional risk exposure. These attributes enter into the risk assessment of the bank and the loan conditions offered to the firm, consisting of size and interest rate for the loan. The firm then selects the bank with the lowest interest rate offer.

On a daily basis, the banks rank their stream of credit requests in ascending order of risk exposure. The least risky credit requests on the current day are considered first, provided the regulatory capital and liquidity requirements are met. Since different firms have different activation days on which they start their production cycle, it could happen that a low-risk firm makes a loan requests one day after some high-risk firm has already obtained a loan. The lowrisk firm may then be credit rationed due to the fact that the bank has reached its limits on total risk exposure. We call this the credit congestion effect since the high-risk firms that come one day earlier cause a credit congestion for the low-risk firms, that are left pining for the funds. This congestion effect is identified by Acharya et al. (2016) as one of the main effects hampering growth in the European periphery countries. 


\subsubsection{Probability of Default}

The firm's probability of default (PD) depends on its creditworthiness measured by its debt-toequity ratio (including the new debt). Following the internal risk-based (IRB) approach of the Basel Accords, a minimum risk-weight for the probability of default is set at 3 basis points $(0.03$ percent). We assume a bank associates the following PD to a loan of size $L_{i t}$ :

$$
P D_{i t}=\max \left\{3 \times 10^{-4}, 1-e^{-\nu\left(D_{i t}+L_{i t}\right) / E_{i t}}\right\} .
$$

The rule is parametrized by a parameter $\nu(\nu=0.1)$ that weighs the impact of the debt-to-equity ratio on the probability of default.

\subsubsection{Credit risk}

We assume there is no collateral for debt, hence debt is unsecured and the expected loss given default (EL) is the full amount of the loan. Due to this assumption, the credit risk or Exposure at Default (EAD) equals the probability of default of the firm multiplied by the loan value:

$$
E A D_{i t}^{b}=P D_{i t} \cdot L_{i t}
$$

The total Risk Exposure Amount (REA) ${ }^{19}$ of the bank is now simply the sum of all risk-weighted assets across the entire loan portfolio:

$$
R E A_{t}^{b}=\sum_{i=1}^{F} \sum_{k=0}^{K(i)} P D_{i t} \cdot L_{k t},
$$

where the index $i$ runs over all firms, and index $k=0, \ldots, K(i)$ over loans of firm $i$ with bank $b$.

\subsubsection{Interest rate rule}

The interest rate offered to a firm is an increasing function of the credit risk reflecting the risk premium that the bank charges to more risky, less financially sound firms. The credit risk posed by firm $i$ enters into the loan conditions as a mark up on the Central Bank base interest rate. The weight of the credit risk in the interest rate can be calibrated by a behavioural parameter $\lambda^{B}$ that is the same across all banks (by default, $\lambda^{B}=3$ ). Furthermore, the time-varying operating costs are captured by a random variable $\epsilon_{t}^{b}$, which is uniformly distributed on the unit interval ${ }^{20}$

$$
r_{i t}^{b}=r^{c}\left(1+\lambda^{B} \cdot P D_{i t}+\epsilon_{t}^{b}\right), \text { where } \epsilon_{t}^{b} \sim U[0,1] .
$$

\subsubsection{Capital Adequacy Requirement}

Each bank is required to satisfy a minimal capital adequacy ratio, implying that banks have to observe a limited exposure to default risk. That is, bank equity (core capital) must be greater or equal to a fraction $\kappa$ of the value of its risk-weighted assets. This assumption is based on Basel II/III capital requirements, where $\kappa$ is between 4 and 10.5 percent. The bank's total exposure to credit risk is restricted by $\alpha:=\kappa^{-1}$ times the equity of the bank:

\footnotetext{
${ }^{19}$ The new term Risk Exposure Amount (REA) is replacing the Risk-Weighted Assets (RWA) as the new terminology in use by the regulatory authorities.

${ }^{20} \mathrm{~A}$ similar specification for the interest rate rule can be found in Delli Gatti et al. (2011, p. 67). The difference with our specification is that we use the probability of default, while they use the leverage ratio.
} 


$$
E_{t}^{b} \geq \kappa \cdot R E A_{t}^{b} \quad \text { i.e. } \quad R E A_{t}^{b} \leq \alpha \cdot E_{t}^{b}
$$

Here $E_{t}^{b}$ is bank equity (core capital), $R E A_{t}^{b}$ is the value of risk-weighted assets, $\kappa$ is the capital adequacy ratio, and $\alpha:=\kappa^{-1}$ is the maximum leverage in terms of total equity to the riskexposure amount. If the constraint is violated the bank stops providing new loans. Pre-existing loans are still administered, firms continue to pay interest and debt installments, and the demand deposits of account holders continue to be serviced. From this we derive a credit risk exposure "budget" $V^{b}$ that is still available to fund firms:

$$
V_{t}^{b}:=\alpha \cdot E_{t}^{b}-R E A_{t}^{b} .
$$

The supply of credit risk in the current period is restricted to this exposure budget $V^{b}$. Firm $i$ receives its full credit whenever the bank's total credit risk exposure remains below this limit and is fully rationed when the loan would exceed the risk limit. In terms of the exposure budget $V^{b}$ the credit offer reads 21

$$
\bar{\ell}_{i t}^{b}= \begin{cases}L_{i t} & \text { if } P D_{i t} \cdot L_{i t} \leq V_{t}^{b} \\ 0 & \text { if } P D_{i t} \cdot L_{i t}>V_{t}^{b}\end{cases}
$$

Bank risk exposure is positively correlated to the capital adequacy ratio $\alpha$. Higher $\alpha$ means more risk is allowed, hence banks have at their disposal a greater budget of excess risk exposure and will tend to give out more risky loans.

\subsubsection{Reserve Requirement}

The banks must observe a minimum Reserve Requirement Ratio (RRR), that is, reserves must exceed a fraction $0 \leq \beta \leq 1$ of total deposits of households and firms:

$$
M_{t}^{b} \geq \beta \cdot D e p_{t}^{b}, \text { where } D e p_{t}^{b}=M_{h t}^{b}+M_{i t}^{b} .
$$

From this an excess liquidity "budget" of the bank is derived as:

$$
W_{t}^{b}:=M_{t}^{b}-\beta \cdot D e p_{t}^{b} \geq 0 .
$$

If the excess liquidity budget is sufficient to provide a firm with its requested credit, then it is serviced in full. Otherwise it is partially credit rationed such that the bank attains its minimum reserve requirement. In case of partial rationing, the granted loan size is given by ${ }^{22}$

$$
\ell_{i, t}^{b}= \begin{cases}\bar{\ell}_{i, t}^{b} & \text { if } W_{t}^{b} \geq \bar{\ell}_{i, t}^{b} \\ W_{t}^{b} & \text { if } 0 \leq W_{t}^{b} \leq \bar{\ell}_{i, t}^{b} \\ 0 & \text { if } W_{t}^{b}<0\end{cases}
$$

\footnotetext{
${ }^{21}$ An alternative behavioural rule for the bank that we have tested is "partial rationing": when the credit risk exceeds the risk exposure budget $V^{b}$, then firm $i$ only receives a proportion of its request, up to the constraint. This rule implies that banks always exhaust their available risk budget and does not result in a viable economy. It leads to more credit rationing rather than less, since firms coming to the bank after a very risky firm has already secured a loan will not be able to receive any loans, because the bank has already exhausted its risk budget.

${ }^{22}$ Note that for the liquidity requirement we use "partial rationing", while for the capital requirement we used "full rationing" for credit requests that would exceed the binding constraint. This implies the equity constraint always has some slackness, while the liquidity constraint can be strictly binding. The reason is that we assume the Central Bank has a fully accommodating monetary policy such that if the bank has a binding liquidity constraint, the Central Bank will always provide it with new reserves. However, the Central Bank will not provide new equity if the bank would have a strictly binding equity constraint, since we do not assume there is an automatic bail-out or other recapitalization mechanism in place.
} 


\section{Macroprudential regulation and mitigation policies}

The main objective of macroprudential policy and regulation is to limit the risks of systemwide crises and, when they do occur, to mitigate the negative effects of such crises. Hence macroprudential policies usually aim at smoothing the financial- and credit cycles, in order to stem the negative externalities of the financial system. Following Dell'Ariccia et al. (2014, p.352), macroprudential policies can broadly be grouped into three categories:

I. Capital and liquidity requirements:

a. capital conservation and counter-cyclical buffers, to build up shock absorption capacity during the cycle.

b. dynamic loan-loss provisions, to shield against unexpected losses.

II. Asset concentration and credit growth limits:

a. credit quotas to impose limits on the volume of credit.

b. speed limits on credit expansion, to prevent high levels of leverage.

c. limits on sectoral concentration of loan portfolios, to prevent overly concentrated exposures.

III. Loan eligibility criteria:

a. credit rationing of certain sectors/firms to improve the quality of borrowers.

b. loan-to-value ratios (LTV), to prevent large loans as a fraction of asset value.

c. debt-to-income limits (DTI), to prevent low-income debtors from obtaining large new loans.

We have already analysed the effectiveness of policy measures in category I (capital and liquidity requirements) in an earlier analysis (van der Hoog and Dawid, 2017). In this paper, we will test policy measures in category II and III.

In Sections 5.1 and 5.2 we test measures in category III(a), namely whether credit rationing of certain firms by cutting off funds to the most highly leveraged firms leads to an improvement in the quality of borrowers, and thereby to an improvement of the stability of the economic system at the macro-level. This policy can be seen as a micro-prudential policy, since it is aimed towards specific firms, but at the same time it could also be seen as a macro-prudential policy since its main focus lies on improving the stability at the macro-level.

In Sections 5.3 and 5.4 we test measures in category II(a,b), whether strict credit growth limits will make the financial system more stable. We do this by comparing two additional scenarios. The first is our "limits to credit growth" scenario, with very strict limits on the credit growth rate by imposing a full reserve requirement and full equity funding. The second scenario is a "highly financialized economy" scenario, without any restrictions on the credit growth rate (no reserve requirement) but maintaining a full equity funding requirement.

\subsection{The Admati \& Hellwig proposals}

In their highly acclaimed book Admati and Hellwig (2013) propose several measures to increase the equity capital in banks, which should increase the stability of the financial system. Below 
we consider some of these proposals, including some of our own, in the context of our model. We first consider the effects of each scenario in isolation and then their combined effects.

Scenario A. Default scenario.

The default scenario is to impose a regulatory capital adequacy requirement of $12.5 \%$ and a minimal reserve requirement of $10 \%$. The capital adequacy ratio is based on the risk-weighted assets (this will differ in scenario $\mathrm{C}$ below).

Scenario B. Banning bank dividend payouts.

A ban on bank dividend payouts would improve the banks' equity, due to retained dividends, so it would be easier to satisfy higher capital ratios. But it is also evident that such a ban does not completely resolve the issue of credit bubbles since it does not address the problem that banks might be funding highly leveraged firms, for example to roll-over their interest payments (speculative finance) or to refinance old debt contracts (Ponzi finance).

Scenario C. Using non-risk-weighted capital ratios.

The second measure is to use a non-risk-weighted capital ratio, instead of using the risk-weighted exposure amount (REA). The motivation is that basing credit regulations on risk-weighted assets makes them prone to manipulation. If banks are allowed to use their own internal risk models they can fine-tune the risk-weights in order to satisfy any capital requirements, a practice which is generally known as "Risk Management Optimization".

Furthermore, regulation on the precise measurements of these risk-weights only makes the regulation more complex, and prone to further manipulation. Therefore, the easiest way to simplify the regulation is to get rid of the risk-weights altogether, and to use the non-riskweighted, total nominal value of all risky assets in the capital ratios instead.

Scenario D. Cut off all funding to financially unsound firms, both speculative and Ponzi.

This alleviates two problems at once: the liquidity congestion effect and the Zombie-lending effect. The liquidity congestion effect is caused by unhealthy firms laying claim to a large proportion of the liquidity budget of the banks, crowding out the healthy firms. The Zombie-lending effect is the risk-counterpart to this, where the unsound firms account for a large proportion of the risk exposure budgets, thwarting the non-risky businesses from getting funding. By cutting off funding to both speculative and Ponzi financed firms, the hedge financed firms should be able to obtain funding more easily.

Scenario E. Cut off all funding to Ponzi firms only.

If the previous measure is found to be overly restrictive, it can be adjusted to only affect the Ponzi firms.

Scenario $F(=B C D)$. Banning bank dividends, Using non-risk-weighted capital ratios, and cut off all funding to financially unsound firms.

Scenario $G(=B C E)$. Banning bank dividends, Using non-risk-weighted capital ratios, and cut off all funding to Ponzi firms.

\section{Definition of Minsky states}

To apply scenarios D and E we classify firms according to their financial positions following Minsky (1978, 1986). These "Minsky states" are defined before the firm visits the credit market: 
- Minsky state $M_{1}$ : the firm uses internal funding to finance production, no new loans are required (pre-existing loans can be serviced in full).

- Minsky state $M_{2}$ : hedge finance, new loans are only needed to pay for the production process (working capital to pay the wage bill and investments).

- Minsky state $M_{3}$ : speculative finance, new loans are needed to pay for debt principle, but not for interest on pre-existing debt.

- Minsky state $M_{4}$ : Ponzi finance, new loans are needed to pay for debt principle and interest payments.

In addition, after the credit market closes, we can identify whether the firm has successfully obtained all requested credit, or whether it has entered into a liquidity crisis - which can always be resolved by downscaling the dividends and/or the planned production - or whether it has entered into bankruptcy ${ }^{23}$

- Firm state $M_{x, 0}$ : the firm has successfully obtained all credit requested.

- Firm state $M_{x, 1}$ : the firm was credit rationed and entered into liquidity crisis.

- Firm state $M_{x, 2}$ : the firm was credit rationed and entered into liquidity bankruptcy.

- Firm state $M_{x, 3}$ : the firm was credit rationed and entered into insolvency bankruptcy.

\subsection{Results for Category III: Loan eligibility criteria}

The macroeconomic dynamics for the default scenario A are shown in Fig. 1. We illustrate the underlying stability of the economy by showing how the total output and unemployment rate vary for variations in the consumer price sensitivity parameter $\gamma$. A low value of $\gamma=18$ indicates a stable economy with average unemployment rates of approx. 10 percent, while high values in the range of $\gamma=20$ yield highly unstable dynamics. The underlying mechanism driving this result is that due to a high price sensitivity of consumers this yields low profit margins for the firms. This causes firms to demand more credit, leading to higher leverage ratios.

The results for the seven scenarios A to $\mathrm{G}$ are summarized in the seven box plots shown in Figure 2, Summarizing the results, we observe that cutting off funding to all speculative and Ponzi financed firms (scenario D) has a highly significant positive effect for reducing the amplitudes of recessions, as well as for reducing the cumulative losses. Cutting off funding to only the Ponzi firms (scenario E) proves less effective, but still shows slightly better results than the default scenario A, or the other options B and C. There is no additional benefit to combining different policy measures, as the results for the combined scenarios $\mathrm{F}$ and $\mathrm{G}$ indicate. We conclude that scenario D is the most successful policy to prevent severe downturns, and to restrict the cumulative economic losses 24

\footnotetext{
${ }^{23}$ In the ex post credit market states the first index $x=2,3,4$ refers to the Minsky states defined above. There are thus $12+1$ states in total, including the firms in Minsky state $M_{1}$ that only use internal funds to finance production. Note that we do not track whether the firm was credit rationed as a result of the bank's liquidity constraint or the equity constraint.

${ }^{24}$ Appendix B reports on an extensive robustness analysis, confirming the result that scenario D is the most successful policy even when varying the parameter settings.
} 


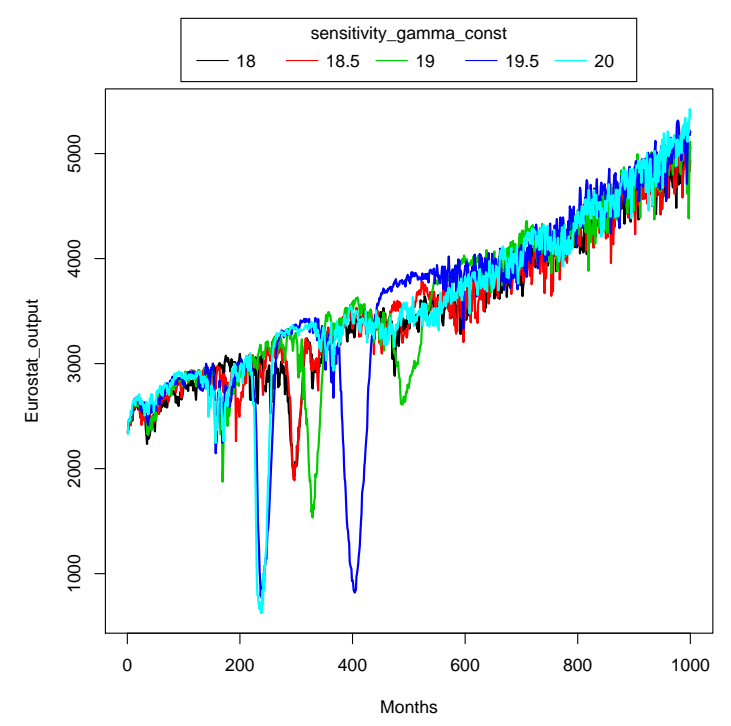

(a) Total output

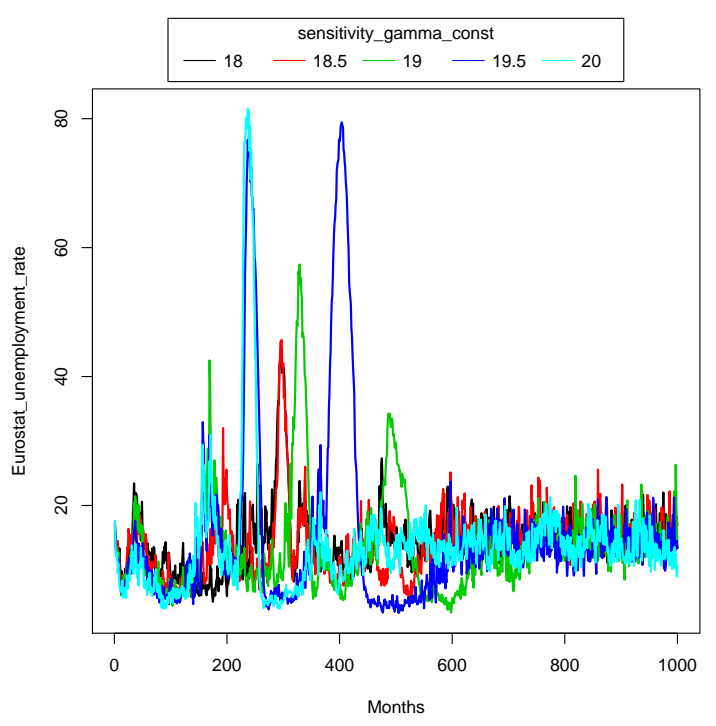

(b) Unemployment rate

Figure 1: Default scenario A. Total output and unemployment rates for variations in the consumer price sensitivity parameter $\gamma$. A low value of $\gamma=18$ indicates a stable economy with average unemployment rates of approx. 10 percent, while high values in the range of $\gamma=20$ yield highly unstable dynamics. Note that these are illustrative results for a single run.

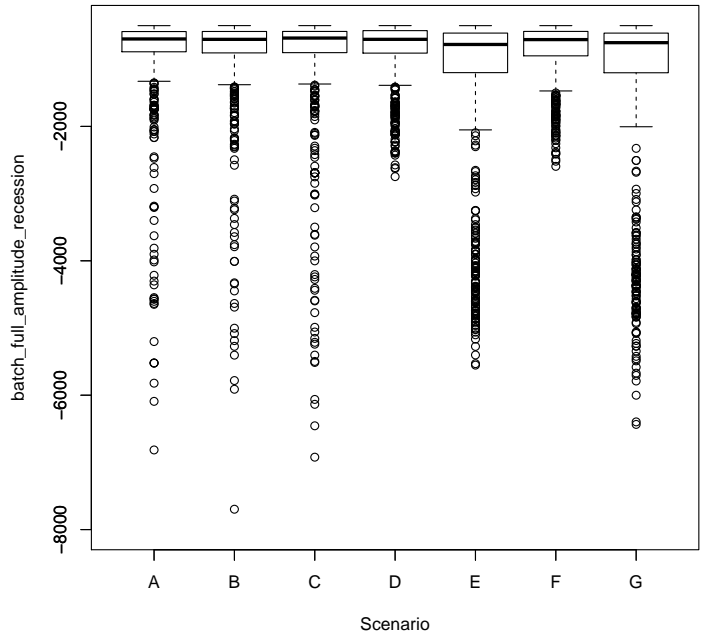

(a)

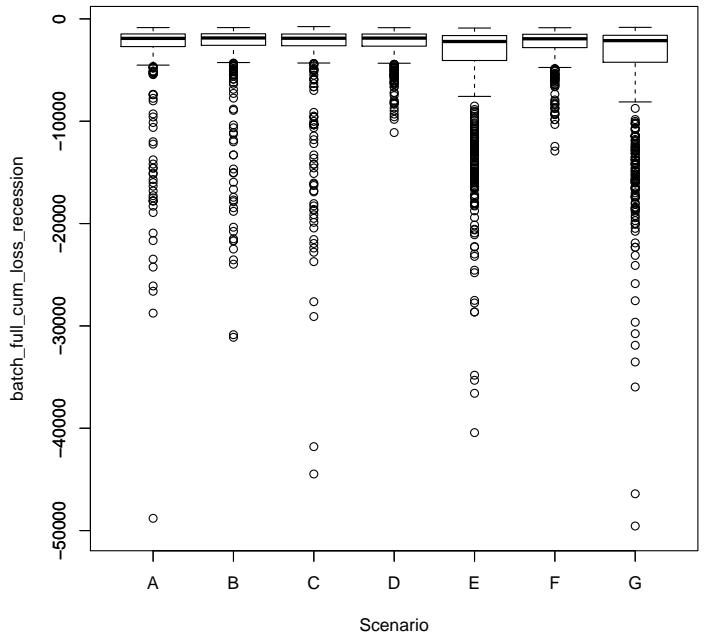

(b)

Figure 2: Box plots for the analysis of the "Admati and Hellwig proposals". Results based on 100 runs; recessions smaller than 500 units are censored. (a) amplitude of recessions (b) cumulative loss of output during recessions. 


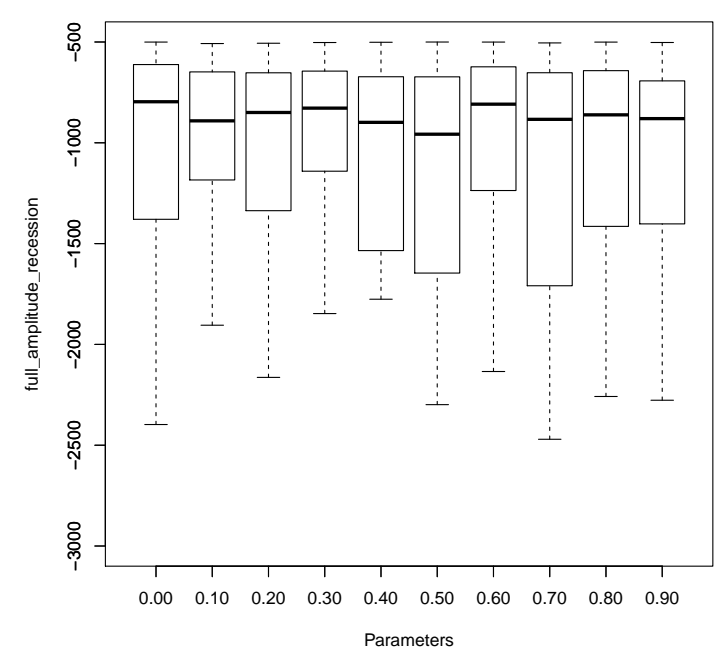

(a)

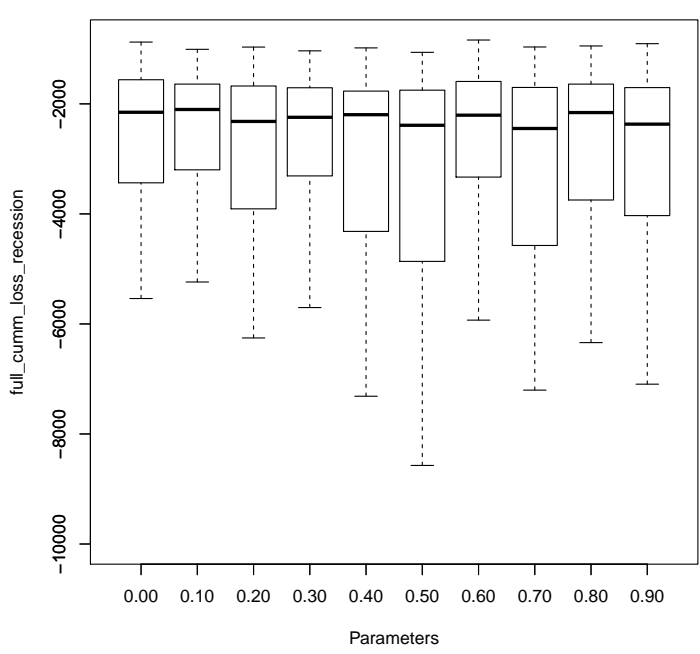

(b)

Figure 3: Box plots for a parameter sensitivity analysis wrt. bank dividends, varying in the range $d^{b}=0, \ldots, 0.90$. (a) amplitude of recessions (b) cumulative loss of output during recessions.

\section{Effect of regulating bank dividends}

In contrast to the drastic measure of banning bank dividends altogether, we might also consider the effect of gradually increasing the bank dividend rate from 0 to 90 percent, in steps of 10 percentage points. Figure 3 illustrates the results of this sensitivity analysis. We conclude that a lower dividend rate the 70 percent does improve the situation somewhat, due to higher bank equity levels, but there is no clear relationship between the dividend rate and the amplitude or cumulative loss due to recessions.

\subsection{The Chicago Plan for Monetary Reform}

The 'crisis in economic theory' (Kirman, 2010) was partly caused by the fact that right up to the financial crisis macroeconomic theory was in a narrowly framed 'fine-tuning' mode, while instead it should have been in a more broadly scoped 'exploration' mode (Caballero, 2010). Taking this into account, finding a solution to the problem of financial stability might require some "out of the box thinking". Below we brainstorm about some unorthodox proposals that might not function in all situations, but that might prove useful as thought experiments for the development of more attainable solutions.

The Full Reserve Banking proposal (Douglas et al., 1939) - also known as the Chicago Plan for Monetary Reform or as "das Vollgeldsystem" in the German-speaking world - implies a full separation of the monetary system into two subsystems, one for deposit-taking and transactionsand payment related activities, and another subsystem for pure credit-creation and lending activities. Institutionally, it would separate the banks into two classes: (i) deposit-taking institutions that offer services for making payments, and (ii) credit-creating companies that provide credit services and true financial intermediation between investors and entrepreneurs. This type of company would be completely funded by equity investors (Klein, 2013).

The regulatory ingredients of such a system are as follows. The first ingredient of Full 
Reserve Banking (FRB) entails a 100\% central bank reserve ratio (Douglas et al., 1939). All deposits are fully covered by central bank reserves. There are no bank runs, no need for deposit insurance, and it ensures the payment system continues to function, no matter what happens in the debt/credit system.

The second ingredient of Full Equity Finance (FEF) entails a 100\% equity capital ratio (Cochrane, 2014). All bank loans are fully covered by equity funds, and we could impose the non-risk-weighted capital ratio. This simplifies the regulatory structure enormously since it abolishes the need for risk-weights and complicated discussions on how to measure them, and there is no longer the possibility of default due to credit risks, even though defaults due to market risks are still possible. All credit risks are covered, so the debt system for investments continues to function, even if debtors would default. The banks can issue new loans only if at the same time they find the capital to fund those loans. This funding might come from investors different than the bank itself, which would turn the bank into a true financial intermediary between investors and entrepreneurs, not between depositors and borrowers as it is usually presented in textbooks. The investors are professionals who know full-well the risks involved in investing into risky business activities. Deposit holders on the other hand are not so well-informed and may not have detailed knowledge of the risks involved. The bank would offer investment accounts that are separate from deposit accounts, and customers can decide how much they would want to invest and in what businesses. The argument that in such a scenario the banks cannot make profits since investors are lending directly to businesses is invalid (Dow et al. 2015). Since loans have to be redeemed at positive interest rates this provides a means for the banks to generate profits. Of course, the investors that put up the funds for the investments will receive part of these interests, but the bank could raise a fee on both the borrowing enterprise and the investor, for its service rendered in bringing the two parties together, and for making the assessment of the credit worthiness of the borrower and monitoring the loan over the course of the debt repayment period. Even though the creation of new loans creates deposits (since the firm will make use of the funds to make real transactions), in this system all loans would be fully covered by equity capital.

This proposal implies a complete separation between money and credit (see Phillips, 1992a b and Laina, 2015), and yields a super-stable system in our simulations (see Section 5.4). It also implies a complete separation between activities related to the payment system and investment activities. The demand deposits in the deposit-taking institutions are fully covered by central bank reserves while the investment institutions are 100 percent equity financed (so not leveraged on the volume of deposits). This implies the latter do not need a bailout. Note however that the above statement does not imply that all central bank reserves are only reserved for covering the demand deposits. The banks could very well have voluntary reserves in excess of their regulatory requirements, and these reserves could be used to fund new loans to firms, or could be lend out to other banks on the interbank market. The reserves might also serve as collateral, or simply be redeemed at the central bank for cash. The voluntary reserves are thus simply another asset on the balance sheet of the bank.

In such a monetary system, an additional requirement could be imposed that credit creation is reserved solely for financing productive investments, and not for financing purely financial activities (cf. Bank of England, 2016). This notwithstanding, the distinction is sometimes hard to make if for example a firm decides to invest in financial instruments in order to insure itself against uncertain future losses. Banks are then no longer 'banks' in the usual sense, with the special privilege of being the sole private sector institutions allowed to create new money. Instead, they are 'private financial companies' (PFCs) producing financial products and services, just like any other corporation in the modern economy. These credit-creation 
companies are free to create new loans on credit, but are restrained to secure the funds from investors prior to making the investment. The company is also free to decide on using its own funds and expose itself to all the risks. This could be implemented by the company borrowing central bank reserves from the central bank or from other financial companies in the interbank market. It could also secure the funds elsewhere with a promise to repay at some later date. Alternatively, the financial company could sell some of its assets. In short, there is a plethora of options such a financial company would have to fund the new credit creation, without having to endanger the savings of depositors.

As a form of prudential regulation, the extent to which such financial companies can create new credit could in principle be subject to limitations by the central bank by imposing credit quota's (see Ryan-Collins et al., 2014 for examples). This implies that if a company requires additional liquidity to create new credit, the central bank would not be fully accommodating. Although this limits the possibility of credit bubbles, no system of regulation and oversight can ever entirely prevent this from happening. A misallocation of credit due to foolish investments by financial companies into non-productive activities remains possible, and it depends to a large extent on the incentive structure whether such bubbles occur, or whether the financial system proves resilient and stable.

\section{The system without reserves}

An alternative to the system with full-reserve banking and full equity finance is to consider the case without any reserve requirements at all (parameters $\alpha=1.0, \beta=0$ ). This is done in order to reflect the situation in Canada, Sweden, and Australia where this is in fact the case. It implies there is still a separation between base money (created by the central bank) and credit money (created by the banks), and banks have to fully fund new credit from their own equity capital, or from new equity by venture capitalists. But the savings of demand deposit holders are no longer secure since banks are no longer required to hold any reserves. One could think of a centralized deposit insurance scheme to cover losses due to bank bankruptcies. However, due to the fact that there is now a full capital ratio, and we could use the non-risk-weighted capital ratio instead of risk-weighted assets, the bank is no longer susceptible to insolvency due to credit risk, but it could still become insolvent due to other sources of risk.

\subsection{Results for Category II: Limits to credit growth}

To test the above regulatory proposals we now impose, in addition, two new scenarios:

- Scenario H: Full equity finance with a 100\% non-risk-weighted capital ratio $(\alpha=1)$, and full reserve banking with a $100 \%$ central bank reserve ratio $(\beta=1)$. This is our "Limits to Credit Growth" economy, with strict liquidity restrictions on the credit growth rate.

- Scenario I: Full equity finance with a 100\% non-risk-weighted capital ratio $(\alpha=1)$, and $0 \%$ central bank reserve ratio $(\beta=0)$. This is our "highly financialized" economy, without any restrictions on the credit growth rate.

For scenario H, the consequences for the economy are shown in Figure 4 (a). The system turns out to be ultra stable without any credit bubbles appearing. This reinforces some of our previous results from van der Hoog and Dawid (2017) which showed that liquidity constraints work much better than equity constraints to induce financial stability by limiting the credit 


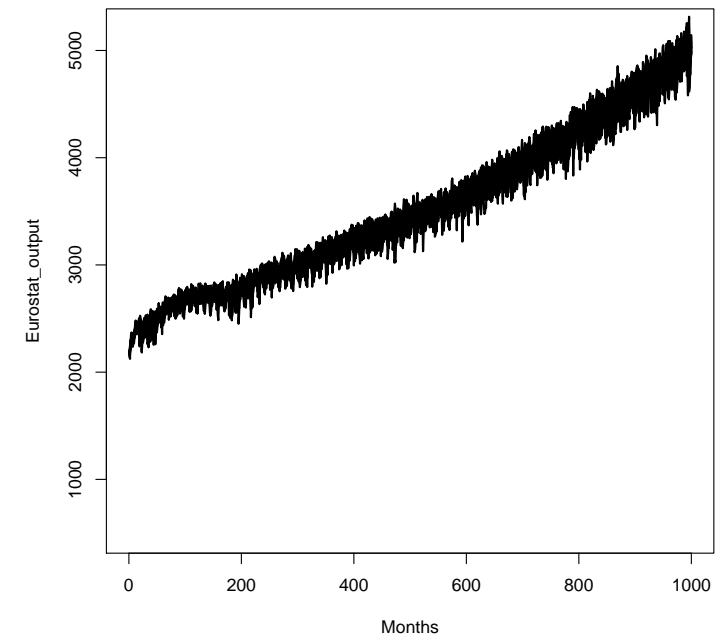

(a) Scenario $\mathrm{H}$

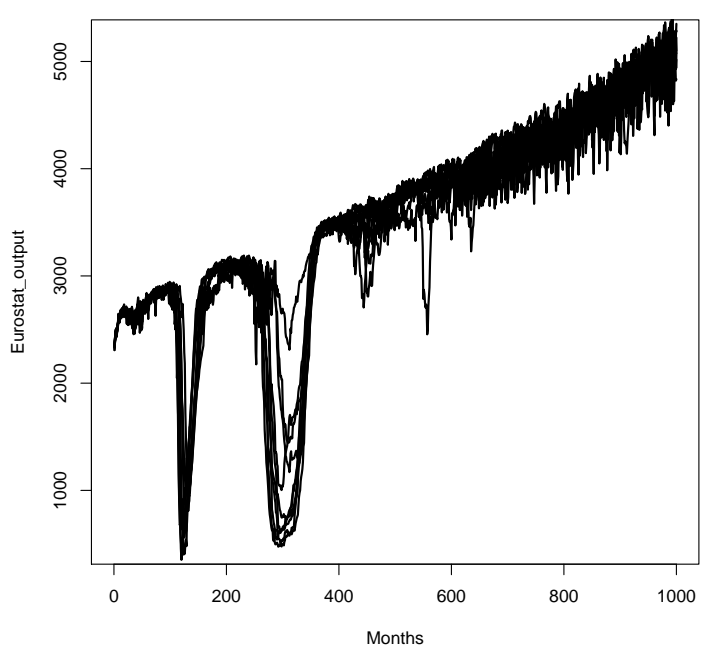

(b) Scenario I

Figure 4: Output levels for two scenarios, for an ensemble of 10 runs. (a) Scenario $\mathrm{H}$ with full equity funding and full reserves $(\alpha=1.0, \beta=1.0)$. (b) Scenario I with full equity funding and no reserves $(\alpha=1.0, \beta=0)$. The plots illustrate that full reserve banking is very stable, while zero percent reserve banking is highly unstable, even when banks are required to use full equity funding to fund new loans.

creating abilities of the banks. The average annualized growth rates of selected macro variables are reported in Table 2, column 2 .

The results for scenario I are reported in Figure 4(b) showing that the $0 \%$ reserve banking system is highly unstable, and severe recessions may occur as a consequence of the absence of limits to credit creation. The annual growth rates for this case are reported in Table 2, column 3. Table 1 provides estimates for the likelihood of each Minsky state's occurrence, for both scenarios. For Scenario H, most firms (52 percent) are in the internal financing state, while 12 percent is in the hedge finance state, 14 percent is in the speculative finance state, and 22 percent is in the Ponzi state. In scenario I fewer firms can finance production using internal funds only (37 percent). Also there are considerably more Ponzi firms (34 percent). This is an indication that in the highly financialized economy firms have increased their leverage and require "ever-greening" of their loans to be able to service their interest and principle debt repayments.

If we now consider what happens after the credit market interaction, we can measure which type of firms is more likely to be credit rationed. We see that in scenario $\mathrm{H}$ the hedge and speculative firms are never credit rationed (100 percent are in state 20 and state 30 , resp.) However, for Ponzi firms 4 percent enter into an illiquidity bankruptcy (state 42). We conclude that even in a highly stable economy with full reserve banking and full equity finance, it is still possible that the high-risk, unhealthy firms may become illiquid and go bankrupt.

In scenario I the occurrence of credit rationing is typically higher, also for the healthy firms. For firms using hedge finance 90 percent experience no credit rationing (state 20) and 10 percent enter into an illiquidity bankruptcy (state 22). For the speculative firms these numbers are approximately the same, with 92 percent not being credit rationed and 8 percent entering into an illiquidity bankruptcy after they have visited the credit market. Finally, for the Ponzi firms, we find that the likelihood of entering into an illiquidity bankruptcy (state 42) is 15 percent. 
Thus, the Ponzi firms are more likely to be credit rationed.

Table 1: Likelihood of occurrence of Minsky states in scenario H and I. States: $1=$ internal financing, $2=$ hedge, $3=$ speculative, $4=$ Ponzi. Minsky states after credit market outcomes: $20=$ hedge firms that are not credit rationed, $21=$ hedge firms that entered into a liquidity crisis, $22=$ hedge firms that entered into illiquidity bankruptcy, $23=$ hedge firms that entered into insolvency bankruptcy. The states 30 till 43 follow a similar logic for the speculative and Ponzi firms, resp. The likelihoods are computed based on the total number of firms observed in each state, for simulations with 80 firms across 1000 observations (months), and considering active firms only.

\begin{tabular}{lrrlrr}
\hline \multicolumn{5}{c}{ Likelihood of Minsky states } \\
\cline { 1 - 5 } & $\mathrm{H}$ & $\mathrm{I}$ & & $\mathrm{H}$ & $\mathrm{I}$ \\
\hline 1 Internal & $52 \%$ & $37 \%$ & 3.0 Not rationed & $100 \%$ & $92 \%$ \\
2 Hedge & $12 \%$ & $16 \%$ & 3.1 Liquidity crisis & $0 \%$ & $0 \%$ \\
3 Speculative & $14 \%$ & $13 \%$ & 3.2 Illiquid & $0 \%$ & $8 \%$ \\
4 Ponzi & $22 \%$ & $34 \%$ & 3.3 Insolvent & $0 \%$ & $0 \%$ \\
\hline 2.0 Not rationed & $100 \%$ & $90 \%$ & 4.0 Not rationed & $96 \%$ & $85 \%$ \\
2.1 Liquidity crisis & $0 \%$ & $0 \%$ & 4.1 Liquidity crisis & $0 \%$ & $0 \%$ \\
2.2 Illiquid & $0 \%$ & $10 \%$ & 4.2 Illiquid & $4 \%$ & $15 \%$ \\
2.3 Insolvent & $0 \%$ & $0 \%$ & 4.3 Insolvent & $0 \%$ & $0 \%$ \\
\hline \hline
\end{tabular}

\section{Real and financial effects of (un-)restricted credit growth}

We now investigate the differences between the "Limits to Credit Growth" economy and the "highly financialized" economy in more detail, considering the macroeconomic context of the real and financial effects. Since scenario H turns out to be very stable, this represents a good starting point to understand how the model works in "normal times". Table 2 shows the average long-run growth rates of several macroeconomic variables (the growth rates are averaged across all runs, and across the time series).

Comparing the highly financialized economy under scenario I with the growth rates under the "Limits to Credit Growth" scenario H, we obtain the following statistics:

- the technological productivity frontier grows with $1.44 \%$ per annum in both scenarios (by construction);

- the economy shows a steady increase in the capital goods price that grows with $3.51 \%$ p.a., which is lower than in $\mathrm{H}(4.65 \%)$;

- total output of firms grows with $1.45 \%$ on average, which is somewhat lower than in $\mathrm{H}$ $(1.70 \%)$;

- the long run average unemployment rate is $14.63 \%$, a bit higher than in scenario $\mathrm{H}$ $(14.08 \%)$; it is also much more volatile.

- the average growth rate of private sector debt is $-0.72 \%$, which is due to the deleveraging that occurs during strong downturns, while in $\mathrm{H}$ the private sector debt increases on average by $1.48 \%$ per annum; 
Table 2: Long-run growth rates in percentage, averaged across all runs.

\begin{tabular}{lrr}
\hline \hline Scenario & $\mathrm{H}$ & $\mathrm{I}$ \\
\hline technological productivity & 1.44 & 1.44 \\
capital goods price & 4.65 & 3.51 \\
total output & 1.70 & 1.45 \\
unemployment rate & 14.08 & 14.63 \\
private sector debt & 1.48 & -0.72 \\
public sector debt & 27.34 & 68.09 \\
stock market index & 13.17 & 29.90 \\
\hline \hline
\end{tabular}

- average growth of the public sector debt is $68.09 \%$ per year, which is much higher than in $\mathrm{H}(27.34 \%)$; this is explained by the benefit payments to the larger number of unemployed in scenario I.

- asset market price inflation is $29.90 \%$ per year, which is double the rate under $\mathrm{H}(13.17 \%)$.

The time evolution of the selected macroeconomic variables are shown in Figures 5 and 6 . We observe that, even in case of full equity funding, it is still possible to generate financial instabilities through credit bubbles by varying the reserve ratio. These credit bubbles are caused by banks' indiscriminate lending and unlimited access to liquidity, being reinforced by the Central Bank's fully accommodating monetary policy. The consequences of the financialization of the economy under scenario I are clearly visible (red curves).

After a steep credit bubble (Fig. 66) the economy collapses and there is a steep decline in output (Fig. 5b) with over 50\% unemployment (Fig. 53). This leads to a quick deleveraging and a write-off of debt, resulting in a direct improvement of the firms' equity to asset ratio (Fig. 6d). The large amount of unemployed households causes a sovereign debt crisis, due to the large amounts of unemployment benefit payments (Fig. 5c and f). Without structural reforms the real economy enters into a double-dip recession with another crash, slightly less deep, but of longer duration (5b) around period 300).

The government is able to achieve a primary surplus only once the economy recovers again (5F, around period 400), but not during the slump. The second crash wipes out a lot of productive firms, which become insolvent. This impairs the banks' balance sheets (Fig. 6b and e). Eventually, banks are able to recover and reboot the creation of new loans to firms. The long run state of the economy is one in which only a handful of banks survive and a few remaining firms. In other words, there is a high level of concentration in both the banking sector and the real production sector. The long run economic outlook consists of debt-fuelled growth funded by the public sector (Fig. 55), along with asset price inflation (Fig. 6f). 

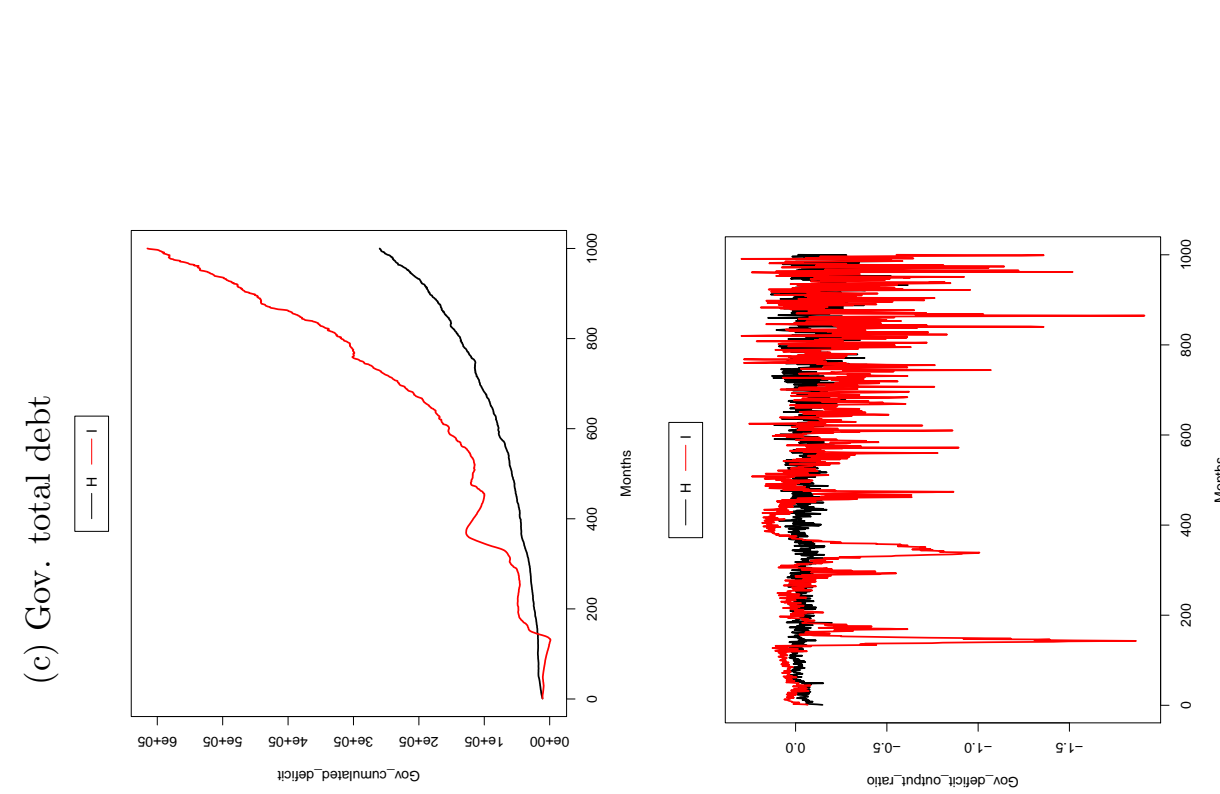

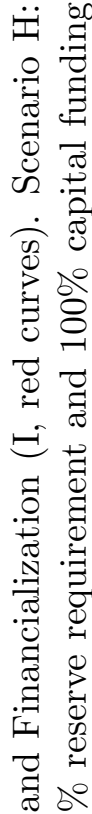
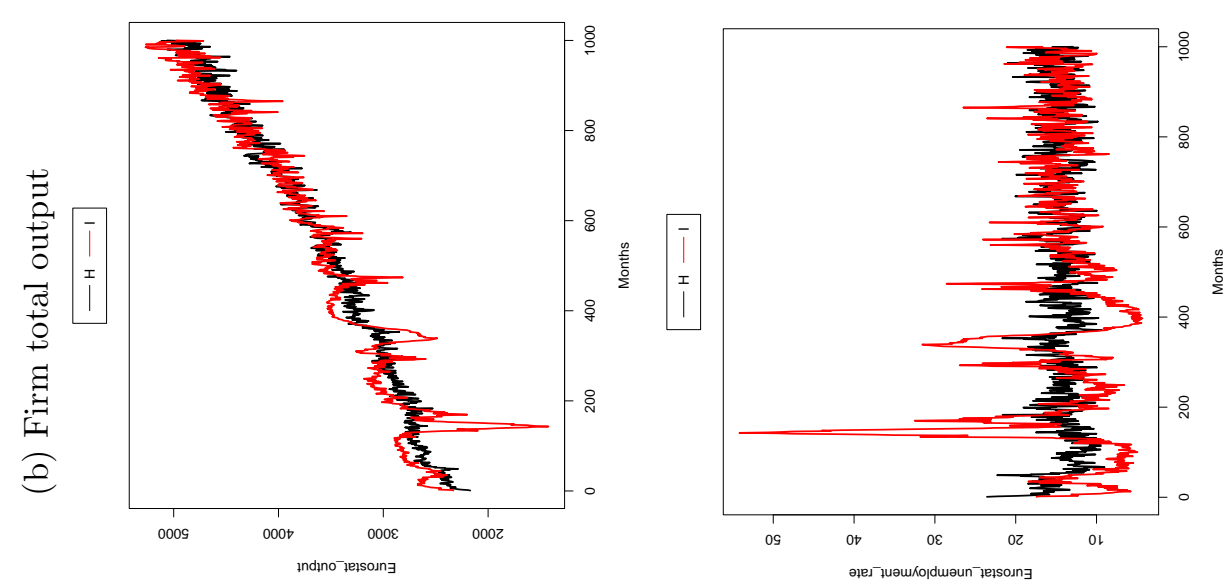

की

을

ฮี ชี จ

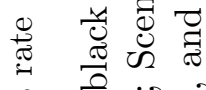

苞 苛 है

द्व $\|$ ज

용

总

(ิ)

:

U.

잉

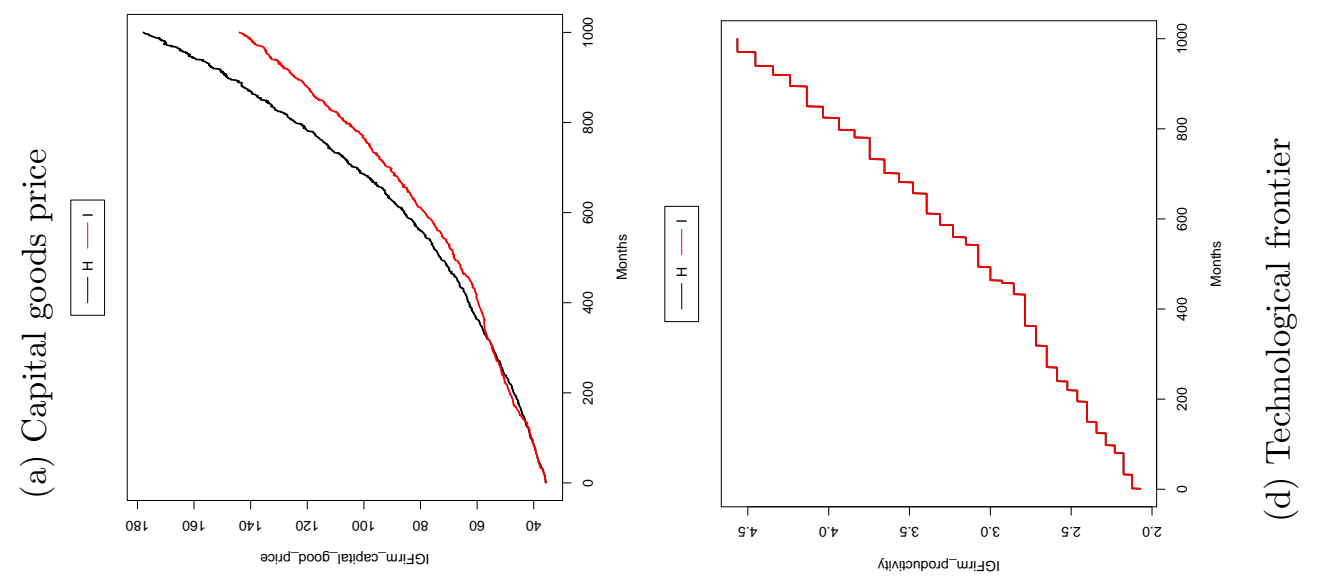

里. .

.] $\exists$

$\because \pi$

番

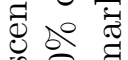

6 8

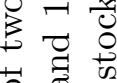

융 苟

焉

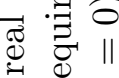

$0=0$

E

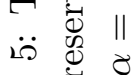

¿

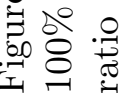



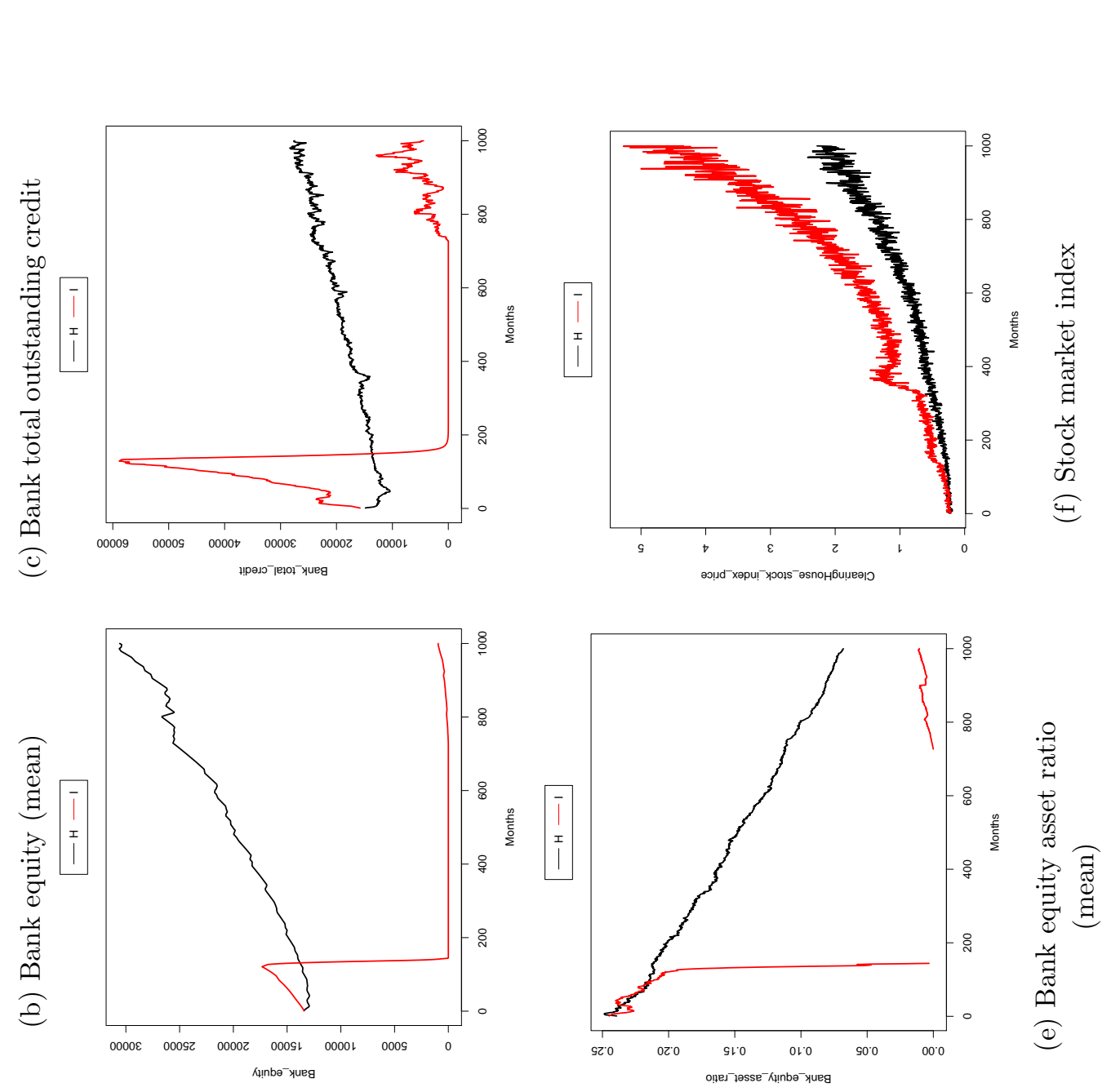

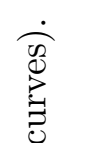

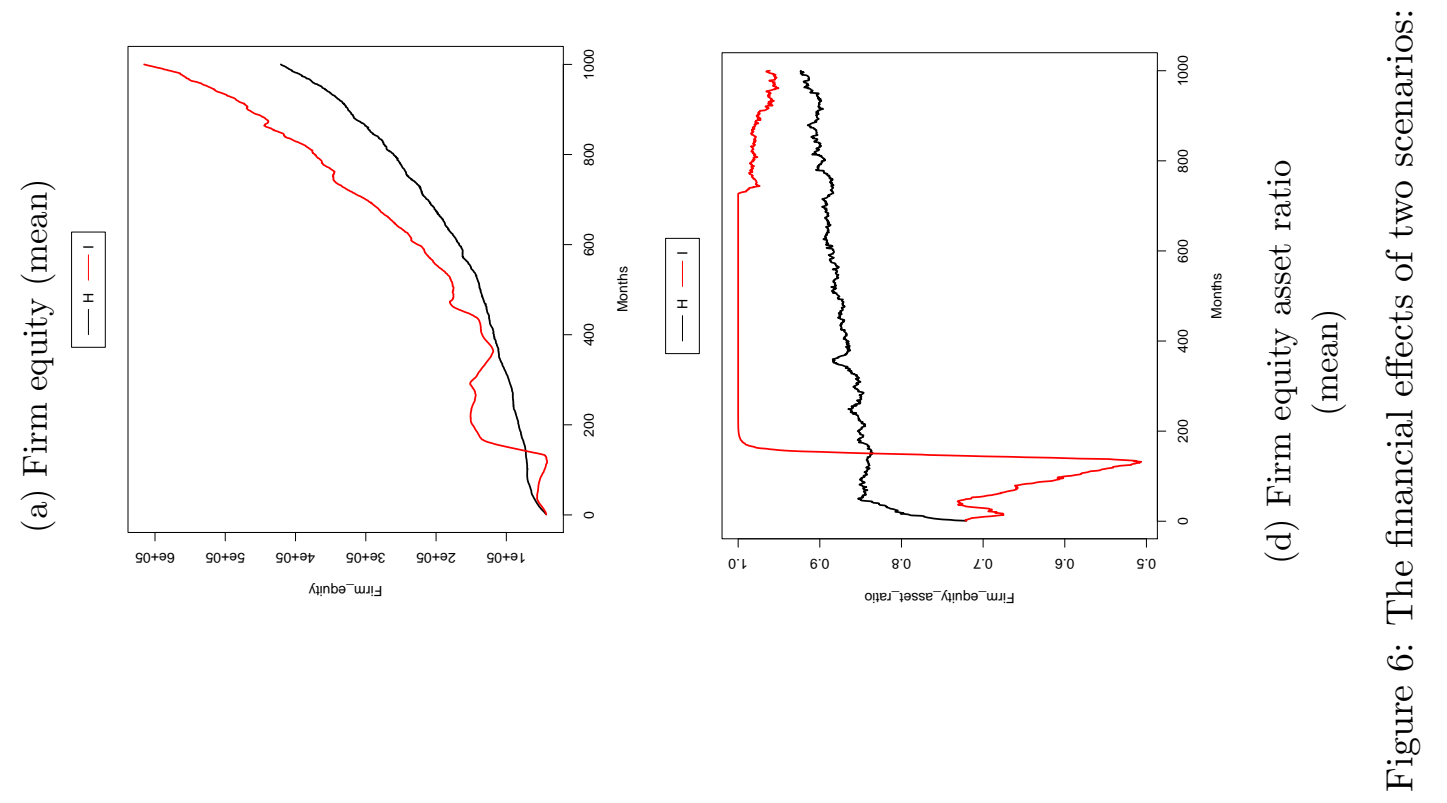




\section{Conclusions}

In this paper we study macrofinancial stability using an agent-based computational model of a closed macroeconomy, using the so called Eurace@Unibi model, by extending it to include macroprudential regulations on the credit market.

We find that the amplitudes of severe downturns that follow leveraging booms are so costly that it seems worthwhile to sacrifice some economic growth on the short run and to restrain the growth of credit in order to prevent the worst downturns from causing large economic losses ${ }^{25}$

In our model, a strengthening of the liquidity requirement does help to generically improve the stability of the system, and to significantly reduce the economic loss in output during severe downturns.

To explain these results we have shown that two mechanisms play an important role, namely a credit-congestion effect and a Zombie-lending effect.

Firstly, the credit-congestion effect occurs on the credit market when the liquidity regulations are lax. If banks have lots of excess liquidity, they tend to use this liquidity to fund both healthy and unhealthy firms. The unhealthy firms are financially unsound and require large sums of liquidity to satisfy their financial commitments. The banks are willing to fund such financially fragile and risky firms because of the higher returns on their investments. It is not clear whether such pure rent-seeking behavior on the part of the banks serves any societal benefits (Cochrane, 2014: Zingales, 2015).

Whereas the riskier firms lay claim to the largest part of the banks' excess reserves of liquidity, the smaller, more financially sound firms are left pining for the funds. Unable to secure funding, some of these smaller firms go out of business and enter into illiquidity bankruptcy as a result.

This congestion effect could be resolved by strengthening the liquidity requirement. That is, by cutting off funding to the unsound firms at an earlier stage in order to prevent the financially sound firms from entering into illiquidity bankruptcies. This is exactly the result we observe in the model, namely that if the reserve requirement is tightened considerably - in our model, to 30 or 50 percent - this results in illiquidity bankruptcies of healthy firms being replaced by insolvencies. We interpret this as a positive result, in the sense that the illiquidities implied an inefficient allocation of credit.

Secondly, the Zombie-lending effect appears in relation to lax capital requirements. This is caused by banks that are allowed to fund large, unsound firms that need new loans to roll-over their existing debt obligations, thereby running up their leverage ratios. If such speculative or Ponzi financed firms would be cut off from funds at an earlier stage and not be kept on artificial life-support they would not be able to survive for long. Hence the term Zombie-firms. The banks keep these firms alive by providing funds at below average interest rates, in order to prevent the loans from becoming non-performing.

Such highly fragile and risky firms account for a large proportion of the banks' risk exposure. If there are no strict limits on banks' leverage ratios, then those firms will keep growing their unsustainable debt volume. But eventually they will become insolvent, possibly resulting in financial contagion due to the large amounts of non-performing loans that result. If such firms would not be allowed to build up such a large amount of debt, the financial contagion could be contained.

The current policy debates about Basel III on counter-cyclical buffers and capital conservation buffers are quite narrowly focussed and highly technical. They focus on the exact values of certain regulatory ratios and do not restrict the banks' ability to create new money. It only

\footnotetext{
${ }^{25}$ These losses can be measured in various ways, from output not produced during the downturn, to the additional number of unemployed, or the total sales foregone.
} 
makes the equity constraint more restrictive. However, as Admati and Hellwig (2013) have forcefully argued, higher capital buffers make banks more solid, so they can actually create more loans, in the long run, because they will be more stable. Our findings point into a similar direction: equity and liquidity constraints work differently, because equity constraints do not discriminate between the borrowing firms. This is so because the constraint is primarily based on the lender's balance sheet and not on the borrower's balance sheet. The firm's balance sheet data only enters through the price, i.e. through the interest rate that depends on the credit default probability. Instead, the liquidity constraint does discriminate between the borrowers, with larger credit request more likely to be rationed.

Exactly this is the main point of this paper: Credit policy should distinguish between productive versus non-productive credit. To support financial stability, credit growth should be cut off from those firms that are speculative or Ponzi financed, which are unproductive, and that use credit for purely financial, speculative purposes. This can be either to roll-over pre-existing debts or to invest in new financial assets. Credit should not be cut off from financially healthy and productive firms, that require new funds for productive activities and employment.

The argument that "the pro-cyclicality of credit is at the root of financial and macro instability" is too simplistic. It is not the quantity of credit that matters, but the quality of credit. The results in this paper show that credit should be channelled to those processes that are economically the most productive, and should be cut off from the unproductive ones. It is part of the social role of banks to figure out towards which firms their credit supply should best be channelled, and to assess the credit worthiness of the debtors. Afterwards they need to monitor the profitability of the firm and its ability to repay the loan. If the borrower cannot repay, it should not indiscriminately receive a novel "extend and pretend" loan to roll-over the old debt, which results in a shift in Minsky states from hedge finance, to speculative finance, and finally to Ponzi finance.

As long as the credit policy remains geared towards regulating the quantity, e.g., through aggregate credit growth targets, or credit quotas per bank, and not towards the quality of the borrowers, the policy is ill-adapted to deal with the specifics of each potential borrower. On the other hand, a focus on the quality of credit requires a detailed look at each credit request, and to assess whether the debtor is using the credit for sufficiently productive purposes that warrant the extension of the credit.

By channelling the productive credit to financially sound firms, the banks can once again perform their social function of supporting economic development, as emphasized by the literature on financial deepening. This is at the same time a micro-prudential policy as well as a macro-prudential policy since it works at the micro-level but also considers the effects on the macro scale. It could result in Schumpeterian dynamics of creative destruction and competition between productive versus unproductive firms, but now with a Minskyan flavour, by dealing with financial fragility as well. 


\section{A Business Cycle Dating Algorithm and Recession Analysis}

The algorithm that was used to obtain the results for this paper is based on well-established methods from the empirical literature to study macroeconomic time series data. A classic reference to business cycle dating algorithms is the original BB algorithm developed by Bry and Boschan (1971). A quarterly Bry-Boschan algorithm, known as the BBQ-algorithm, was proposed by Harding and Pagan (2002). We adopt a similar methodology to time series data analysis as in Claessens et al. (2012). The only difference is that we use the synthetic data being generated by our simulation model, while normally such algorithms are used on empirical data.26

\section{Terminology and Definitions}

The following definitions are taken from Claessens et al. (2012, p.10-12). The definitions can either be based on the time series of the units of output produced, or on actual sales levels. In our time series analysis, we have used the output-based definitions. ${ }^{27}$

Peaks and troughs $\mathrm{A}$ peak in a timeseries $y_{t}$ occurs at time $\mathrm{t}$ if there are 2 periods of increase before, and 2 periods of decrease after $t$ :

$$
\left(y_{t}-y_{t-2}>0, y_{t}-y_{t-1}>0\right) \text { and }\left(y_{t+2}-y_{t}<0, y_{t+1}-y_{t}<0\right)
$$

A trough in a timeseries $y_{t}$ occurs at time $\mathrm{t}$ if there are 2 periods of decrease before, and 2 periods of increase after t:

$$
\left.\left(y_{t}-y_{t-2}<0, y_{t}-y_{t-1}<0\right) \text { and }\left(y_{t+2}-y_{t}>0, y_{t+1}-y_{t}>0\right)\right)
$$

Recession A recession/downturn is the period between a peak a trough.

Expansion An expansion/upturn is the period between a trough and a peak.

Recovery A recovery is the early part of the expansion phase, defined as the time it takes for output to rebound from the trough to the peak level before the recession.

Duration of recessions The duration of a recession/downturn is the number of quarters, $\mathrm{k}$, between a peak $\left(y_{0}\right)$ and the next trough $\left(y_{k}\right)$ of a variable.

Duration of recoveries The duration of a recovery/upturn is the number of quarters $(r)$ it takes for a variable to reach its previous peak level after the trough: $\left\{r>k: y_{r} \geq y_{0}\right\}$.

Amplitude for recessions The amplitude of a recession/downturn $A_{c}$, measures the change in $y_{t}$ from a peak $\left(y_{0}\right)$ to the next trough $\left(y_{k}\right): A_{c}=y_{k}-y_{0}$

Amplitude for recoveries The amplitude of a recovery/upturn, $A_{u}$, measures the change in $y_{t}$ from a trough to the level reached in the first four quarters of an expansion $\left(y_{k+4}\right)$ : $A_{u}=y_{k+4}-y_{k}$.

Slope for recessions The slope of a recession/downturn is the ratio of the amplitude to the duration of the recession/downturn: $S_{c}=A_{c} / D_{c}$.

Slope for recoveries The slope of a recovery/upturn is the ratio of the change of a variable from the trough to the quarter at which it attains its last peak divided by the duration: $S_{r}=$ $\left(y_{r}-y_{0}\right) / D_{u}$. The slope is an approximation of the average economic growth rate over the duration of the recovery.

\footnotetext{
${ }^{26}$ The code for the recession analysis is included in the source code that is available from our website.

${ }^{27}$ The results are robust against using output levels or actual sales.
} 
Cumulative loss for recessions The cumulative loss for a recession with duration $k$ combines the duration and amplitude as a measure for the overall costs of recession: $F^{c}=\sum_{j=1}^{k}\left(y_{j}-\right.$ $\left.y_{0}\right)-A^{c} / 2$, where $y_{0}$ is the level of output at the start of the recession, and $y_{j}$ are the successive terms during the recession.

\section{Detecting peaks and troughs}

Fig 7 shows the detection of peaks and troughs in the time series of output for the business cycle (Panel a) and for the time series of total debt for the financial cycle (Panel c). Fig.7 (Panel b) shows expansions and recessions from peak to trough for the business cycle. This plot does not coincide exactly with the peaks and troughs detected in Fig.7 (a) due to the fact that sometimes two peaks can follow each other without having a trough in the middle. This is because the trough does not necessarily signal a recession, since it might be too short. In such cases the event is censored, i.e. removed from the plot. Fig.7 (c-d) provides the same type of analysis for the credit cycle. Here the solid lines coincide with peaks in the credit cycle, i.e. with the start of a downturn. Dotted lines indicate troughs in the credit cycle, i.e. the start of an upturn or recovery.

\section{B Robustness analysis}

In this section we provide a robustness analysis of the results presented in the main text. As parameter settings we consider all combinations for $\alpha=(0,8.0)$ and $\beta=(0,0.1,1)$, yielding 6 cases. Combining this with the scenarios $A$ through $G$ ( 7 scenarios), this yields 42 scenarios in total.

As statistics for the analysis we consider the amplitude and cumulative loss as metrics for recession severity. Fig 8 shows boxplots for the recession amplitudes and cumulative losses for each of the 42 scenarios. In Table 3 we report the extreme value of the lower whisker of the distribution of each metric. For the recession duration we report the median values. All distributions are based on 100 simulation runs and the full ensemble of recessions observed during the runs is considered. The minimal required recession duration is set to two quarters, and the minimal required amplitude is set to 500 units. Recessions with downturns smaller than 500 units are censored from the distribution.

The scenarios $A$ to $G$ from the main text correspond to group 5 (rows $29-35$ ). Scenario I $(\alpha=1, \beta=0)$ corresponds to row 1 in group 1 , and scenario $\mathrm{H}(\alpha=1, \beta=1)$ corresponds to row 1 in group 3. Table 4 shows descriptive statistics for the recession amplitudes, while Table 5 shows the descriptive statistics for cumulative losses. In each table the overall best policy within each group is indicated with a star $(\star)$, while a dagger $(\dagger)$ indicates the best single policy (from A, B, C, D, E). The ranking criterion for Table 3 is the smallest absolute value of the lower whisker, for Table 4 it is the smallest absolute value of the minimum amplitude, and for Table 5 it is the smallest absolute value of the cumulative loss.

Three main conclusions can be drawn from this robustness analysis. First, Table 3 shows that the ranking is rather robust between groups. The ranking we obtain for the default parameter setting (group 5) is maintained for three other parameter settings, including scenario I (groups 1, 2 and 4). For these cases, the overall best scenario is F (a mixed scenario), followed by the best single policy D (cutting off funding to all financially unhealthy firms). Second, for the remaining two parameter settings (group 3 and 6) the overall best scenario is the single policy $\mathrm{C}$ (using non-risk weighted capital ratios). The latter two groups have in common that they feature the full reserve requirement $(\beta=1)$. Third, if we consider the cumulative loss as the 
ranking criterion, the overall best scenario for most parameter settings is again policy D (cutting off funding to all financially unhealthy firms). The only groups for which this is not the case are groups 3 and 6 , for which $\mathrm{A}$ is the overall best policy (no intervention).

Therefore, the main conclusion to draw from this extensive robustness analysis is that cutting off the funding to financially unhealthy firms and using a non-risk-weighted capital ratio are the two most promising candidates for reducing the amplitude and cumulative losses due to recessions.

(a) Business cycle, peaks and troughs

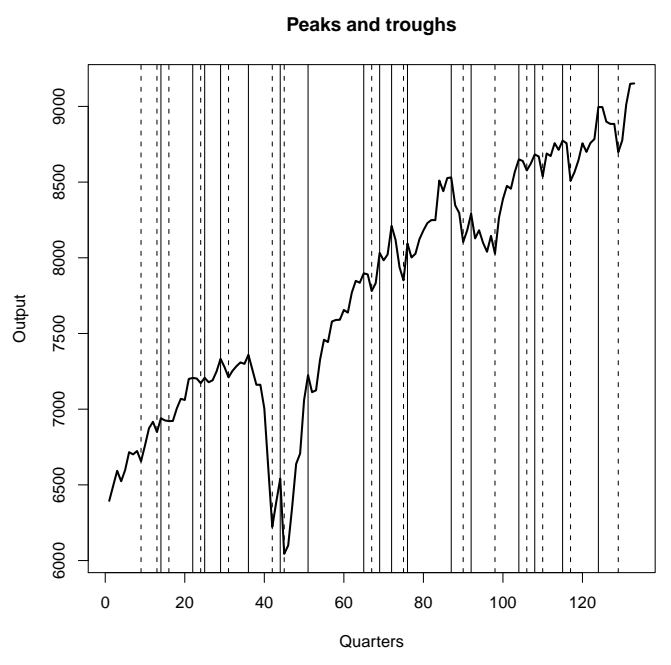

(c) Credit cycle, peaks and troughs

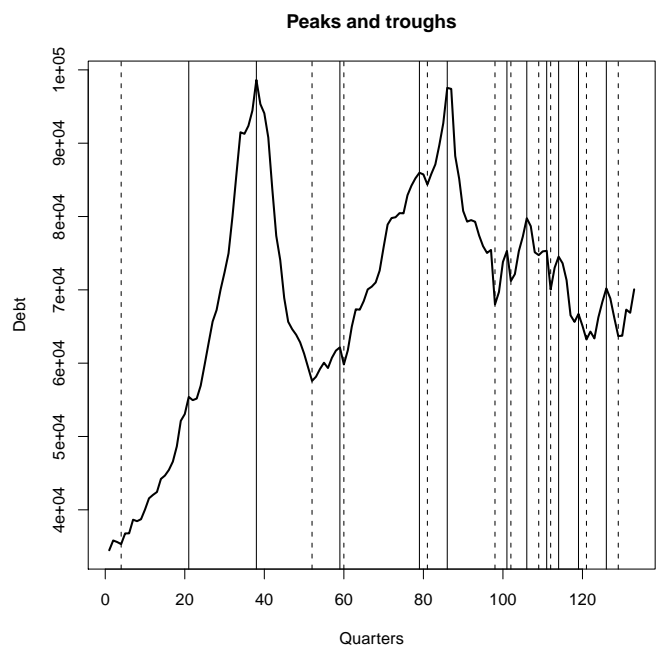

(b) Business cycle, recessions and expansions

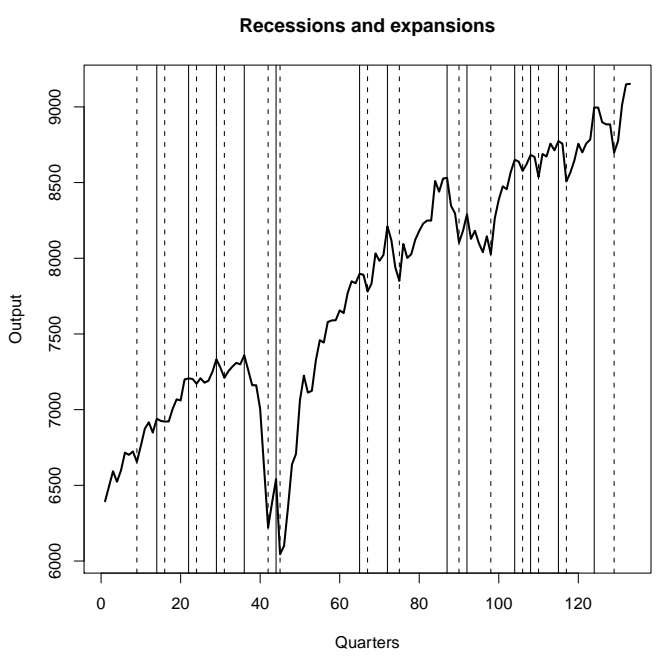

(d) Credit cycle, upturns and downturns

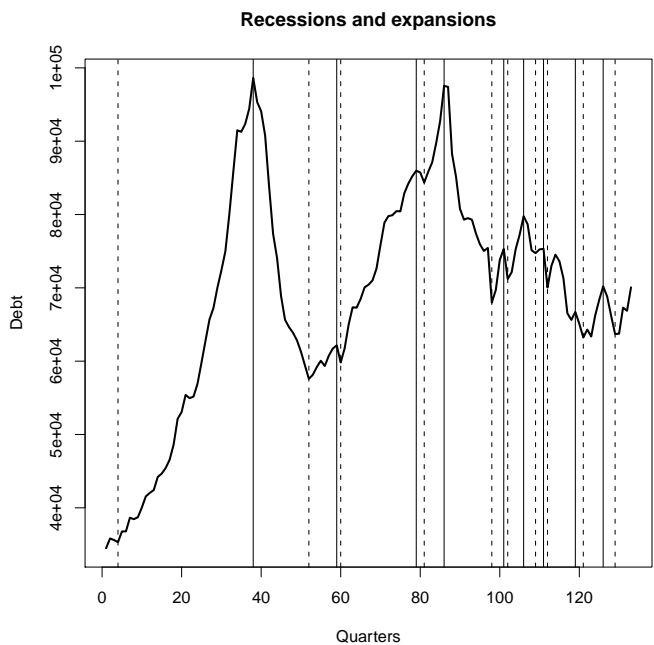

Figure 7: Peaks and troughs for the business cycle and the financial cycle, for 500 months (167 quarters). Solid lines: peaks, or start of a recession; dotted lines: troughs, or start of an expansion. (a-c) Detection of peaks and troughs. (b-d) Recessions and expansions (for the business cycle), and upturns and downturns (for the financial cycle). 

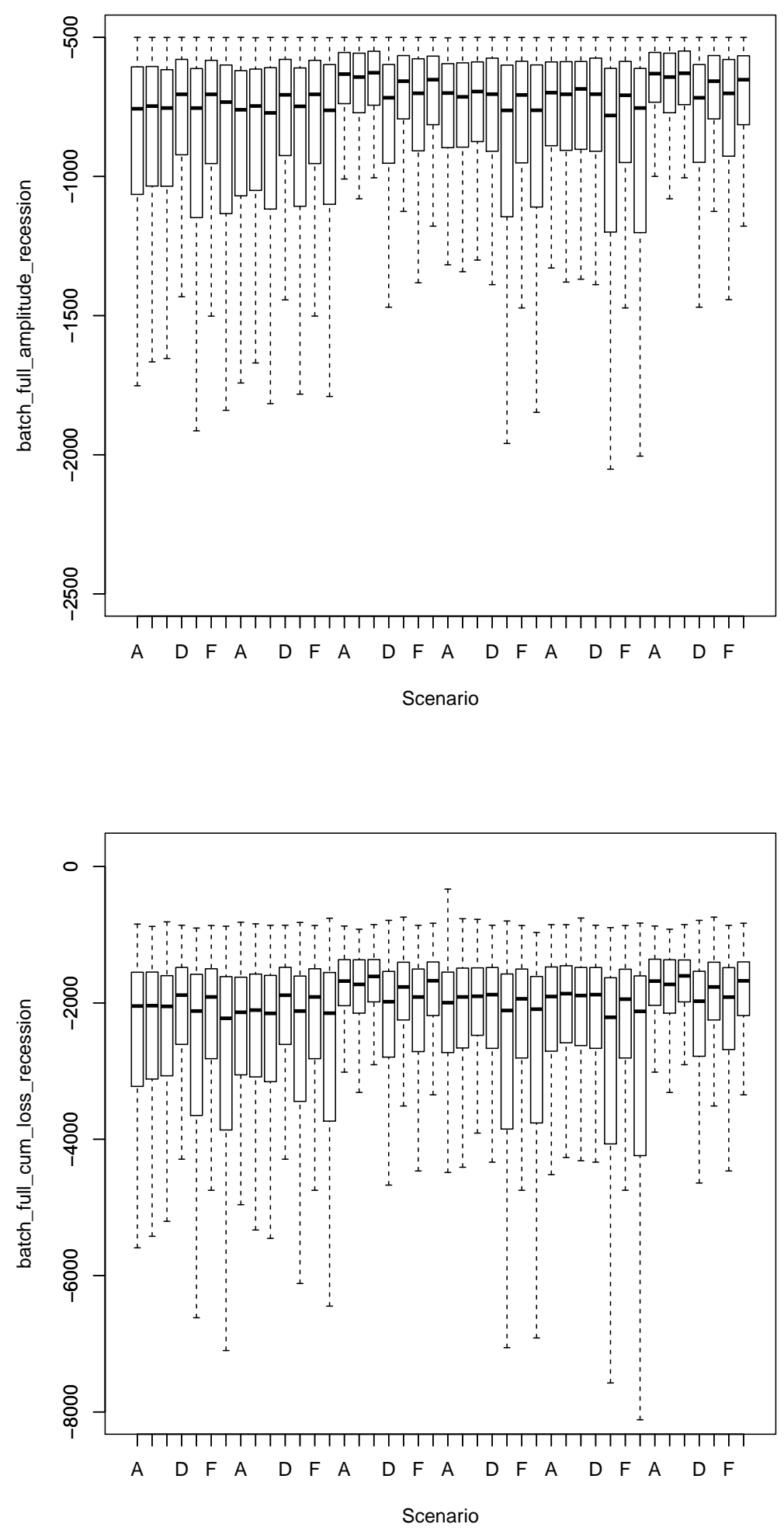

Figure 8: Boxplots of (a) recession amplitudes and (b) cumulative economic losses. Parameter settings: $(\alpha, \beta)=\{1,8\} \times\{0,0.1,1\}$. The scenarios $A$ till $G$ for the default setting $(\alpha=8$, $\beta=0.1)$ correspond to sets $29-35$. Scenario I for $(\alpha=1, \beta=0)$ corresponds to set 1 and scenario $\mathrm{H}$ for $(\alpha=1, \beta=1)$ corresponds to set 15 . Downturns less than 500 units are censored. 
Table 3: Summary statistics for recession data across 100 simulation runs. Rows correspond to 42 scenarios, derived from the scenarios $A$ to $G$ for six parameter settings: $\alpha=(1,8), \beta=(0,0.1,1)$. Reported values are the extremes of the lower whisker of the distribution for each recession metric. A star $(\star)$ indicates the overall best policy within each group, while a dagger $(\dagger)$ indicates the best single policy (from ABCDE). The primary ranking criterion is the smallest absolute value of the lower whisker.

\begin{tabular}{|c|c|c|c|c|c|c|}
\hline \multicolumn{7}{|c|}{ Recession statistics - Lower whisker values of full distribution } \\
\hline Parameters & Scenario & Obs. & Dur. & Ampl. & Slope & Cum. loss \\
\hline \multirow[t]{7}{*}{$\alpha=1 \beta=0$} & $\mathrm{~A}(=\mathrm{I})$ & 773 & 3 & -8193 & -1461 & -82575 \\
\hline & B & 780 & 3 & -7660 & -1516 & -64679 \\
\hline & $\mathrm{C}$ & 796 & 3 & -7540 & -1475 & -58416 \\
\hline & $\mathrm{D} \dagger$ & 759 & 3 & -2747 & -797 & $-11106 \star$ \\
\hline & $\mathrm{E}$ & 848 & 4 & -6563 & -1583 & -56894 \\
\hline & $\mathrm{F} \star$ & 716 & 3 & -2594 & -725 & -12913 \\
\hline & G & 817 & 4 & -7189 & -1563 & -48557 \\
\hline \multirow[t]{7}{*}{$\alpha=1 \beta=0.1$} & $\mathrm{~A}$ & 774 & 3 & -8061 & -1372 & -79044 \\
\hline & B & 745 & 3 & -7337 & -2126 & -67093 \\
\hline & $\mathrm{C}$ & 774 & 3 & -7770 & -1314 & -66989 \\
\hline & $\mathrm{D} \dagger$ & 754 & 3 & -2747 & -797 & $-11106 \star$ \\
\hline & $\mathrm{E}$ & 859 & 4 & -6438 & -1583 & -46247 \\
\hline & $\mathrm{F} \star$ & 716 & 3 & -2594 & -725 & -12913 \\
\hline & $\mathrm{G}$ & 780 & 4 & -7189 & -1689 & -48557 \\
\hline \multirow[t]{7}{*}{$\alpha=1 \beta=1$} & $\mathrm{~A}(=\mathrm{H})$ & 437 & 3 & -1382 & -393 & $-4625 \star$ \\
\hline & B & 481 & 3 & -1807 & -602 & -4991 \\
\hline & $\mathrm{C} \star$ & 460 & 3 & -1334 & -445 & -6541 \\
\hline & $\mathrm{D}$ & 783 & 3 & -2612 & -667 & -10169 \\
\hline & $\mathrm{E}$ & 604 & 3 & -1846 & -559 & -8454 \\
\hline & $\mathrm{F}$ & 725 & 3 & -2697 & -740 & -13281 \\
\hline & $\mathrm{G}$ & 571 & 3 & -1442 & -481 & -11142 \\
\hline \multirow[t]{7}{*}{$\alpha=8 \beta=0$} & $\mathrm{~A}$ & 781 & 3 & -6104 & -1220 & -29342 \\
\hline & B & 731 & 3 & -6638 & -1034 & -50773 \\
\hline & $\mathrm{C}$ & 758 & 3 & -7147 & -1142 & -45760 \\
\hline & $\mathrm{D} \dagger$ & 762 & 3 & -2747 & -797 & $-11106 \star$ \\
\hline & $\mathrm{E}$ & 848 & 4 & -5885 & -1583 & -45943 \\
\hline & $\mathrm{F} \star$ & 719 & 3 & -2594 & -725 & -12913 \\
\hline & $\mathrm{G}$ & 798 & 4 & -6434 & -1535 & -46403 \\
\hline \multirow[t]{7}{*}{$\alpha=8 \beta=0.1$} & $\mathrm{~A}$ & 760 & 3 & -6815 & -1940 & -48800 \\
\hline & B & 781 & 3 & -7697 & -1297 & -31112 \\
\hline & $\mathrm{C}$ & 726 & 3 & -6922 & -1384 & -44470 \\
\hline & $\mathrm{D} \dagger$ & 762 & 3 & -2747 & -797 & $-11106 \star$ \\
\hline & $\mathrm{E}$ & 784 & 4 & -5552 & -1583 & -40426 \\
\hline & $\mathrm{F} \star$ & 723 & 3 & -2594 & -725 & -12913 \\
\hline & G & 788 & 4 & -6434 & -1689 & -49550 \\
\hline \multirow[t]{7}{*}{$\alpha=8 \beta=1$} & $\mathrm{~A}$ & 431 & 3 & -1382 & -393 & $-4625 \star$ \\
\hline & B & 481 & 3 & -1807 & -602 & -4991 \\
\hline & $C \star$ & 455 & 3 & -1334 & -445 & -6541 \\
\hline & $\mathrm{D}$ & 783 & 3 & -2612 & -667 & -10169 \\
\hline & $\mathrm{E}$ & 604 & 3 & -1846 & -559 & -8454 \\
\hline & $\mathrm{F}$ & 714 & 3 & -2697 & -740 & -13281 \\
\hline & G & 576 & 3 & -1442 & -481 & -11142 \\
\hline
\end{tabular}


Table 4: Summary statistics for recession amplitudes in 42 scenarios. Each row shows the summary statistics for 100 Monte Carlo replication runs. A star $(\star)$ indicates the best policy within each group, while a dagger $(\dagger)$ indicates the best single policy (from ABCDE). The ranking criterion is the smallest absolute minimum value of the recession amplitude.

\begin{tabular}{|c|c|c|c|c|c|c|c|c|}
\hline \multicolumn{9}{|c|}{ Recession amplitude } \\
\hline Parameters & Scenario & Obs. & Min & $25 \%$ & Median & Mean & $75 \%$ & $\operatorname{Max}$ \\
\hline \multirow[t]{7}{*}{$\alpha=1 \beta=0$} & $\mathrm{~A}(=\mathrm{I})$ & 773 & -8193 & -1064 & -1064 & -1278 & -606 & -500 \\
\hline & $\mathrm{B}$ & 780 & -7660 & -1034 & -1034 & -1279 & -604.9 & -500.3 \\
\hline & $\mathrm{C}$ & 796 & -7540 & -1035 & -1035 & -1349 & -616.3 & -500.5 \\
\hline & $\mathrm{D} \dagger$ & 759 & -2747 & -922.1 & -922.1 & -853.5 & -579.2 & -500 \\
\hline & $\mathrm{E}$ & 848 & -6563 & -1147 & -1147 & -1292 & -612.2 & -500 \\
\hline & $\mathrm{F} \star$ & 716 & -2594 & -952.4 & -952.4 & -853.8 & -582.8 & -500.5 \\
\hline & G & 817 & -7189 & -1133 & -1133 & -1299 & -599.5 & -500.7 \\
\hline \multirow[t]{7}{*}{$\alpha=1 \beta=0.1$} & $\mathrm{~A}$ & 774 & -8061 & -1068 & -1068 & -1316 & $\begin{array}{l}-619.7 \\
\end{array}$ & -500 \\
\hline & $\mathrm{B}$ & 745 & -7337 & -1050 & -1050 & -1261 & -614.1 & -501.4 \\
\hline & $\mathrm{C}$ & 774 & -7770 & -1116 & -1116 & -1376 & -609.1 & -500.2 \\
\hline & $\mathrm{D} \dagger$ & 754 & -2747 & -924.8 & -924.8 & -855.1 & -579.4 & -500.3 \\
\hline & $\mathrm{E}$ & 859 & -6438 & -1107 & -1107 & -1273 & -610 & -500.3 \\
\hline & $\mathrm{F} \star$ & 716 & -2594 & -952.4 & -952.4 & -853.8 & -582.8 & -500.5 \\
\hline & $\mathrm{G}$ & 780 & -7189 & -1098 & -1098 & -1321 & -598.2 & -501.3 \\
\hline \multirow[t]{7}{*}{$\alpha=1 \beta=1$} & $\mathrm{~A}(=\mathrm{H})$ & 437 & -1382 & -738.3 & -738.3 & -671.2 & -554.5 & -500.1 \\
\hline & $\mathrm{B}$ & 481 & -1807 & -771 & -771 & -687.1 & -557 & -500.2 \\
\hline & $\mathrm{C} \star$ & 460 & -1334 & -743.9 & -743.9 & -666.8 & -550.4 & -500.2 \\
\hline & $\mathrm{D}$ & 783 & -2612 & -952.4 & -952.4 & -867.9 & -597.7 & -500.1 \\
\hline & $\mathrm{E}$ & 604 & -1846 & -792.8 & -792.8 & -705.2 & -565.5 & -500.3 \\
\hline & $\mathrm{F}$ & 725 & -2697 & -907.9 & -907.9 & -858.5 & -577.1 & -500.2 \\
\hline & $\mathrm{G}$ & 571 & -1442 & -813.9 & -813.9 & -702.8 & -567.5 & -500.4 \\
\hline \multirow[t]{7}{*}{$\alpha=8 \beta=0$} & $\mathrm{~A}$ & 781 & -6104 & -896.5 & -896.5 & -952.9 & -594.7 & -501.7 \\
\hline & $\mathrm{B}$ & 731 & -6638 & -894.6 & -894.6 & -930.5 & -591.7 & -500.2 \\
\hline & $\mathrm{C}$ & 758 & -7147 & -873.7 & -873.7 & -917.5 & -588.3 & -500.1 \\
\hline & $\mathrm{D} \dagger$ & 762 & -2747 & -908.5 & -908.5 & -849.6 & -574.9 & -500 \\
\hline & $\mathrm{E}$ & 848 & -5885 & -1144 & -1144 & -1275 & -600.7 & -500 \\
\hline & $\mathrm{F} \star$ & 719 & -2594 & -951.1 & -951.1 & -854.5 & -586 & -500.5 \\
\hline & G & 798 & -6434 & -1109 & -1109 & -1306 & -599.2 & -500.9 \\
\hline \multirow[t]{7}{*}{$\alpha=8 \beta=0.1$} & $\mathrm{~A}$ & 760 & -6815 & -889 & -889 & -917.2 & -588.5 & -500.7 \\
\hline & B & 781 & -7697 & -906.2 & -906.2 & -913.4 & -587.4 & -500 \\
\hline & $\mathrm{C}$ & 726 & -6922 & -902.5 & -902.5 & -963.5 & -587.2 & -500.2 \\
\hline & $\mathrm{D} \dagger$ & 762 & -2747 & -908.5 & -908.5 & -849.6 & -574.9 & -500 \\
\hline & $\mathrm{E}$ & 784 & -5552 & -1199 & -1199 & -1314 & -612.1 & -500.6 \\
\hline & $\mathrm{F} \star$ & 723 & -2594 & -950 & -950 & -854.9 & -586.5 & -500.5 \\
\hline & G & 788 & -6434 & -1201 & -1201 & -1324 & -611.7 & -500.4 \\
\hline \multirow[t]{7}{*}{$\alpha=8 \beta=1$} & $\mathrm{~A}$ & 431 & -1382 & -733.2 & -733.2 & -669.6 & -554.3 & -500.1 \\
\hline & $\mathrm{B}$ & 481 & -1807 & -771 & -771 & -687.1 & -557 & -500.2 \\
\hline & $\mathrm{C} \star$ & 455 & -1334 & -741.8 & -741.8 & -666.1 & -549.3 & -501 \\
\hline & $\mathrm{D}$ & 783 & -2612 & -949.2 & -949.2 & -867.1 & -597.9 & -500.1 \\
\hline & $\mathrm{E}$ & 604 & -1846 & -792.8 & -792.8 & -705.2 & -565.5 & -500.3 \\
\hline & $\mathrm{F}$ & 714 & -2697 & -926.4 & -926.4 & -860.9 & -579.8 & -500.2 \\
\hline & $\mathrm{G}$ & 576 & -1442 & -813.7 & -813.7 & -702.2 & -566.5 & -500.4 \\
\hline
\end{tabular}


Table 5: Summary statistics for recession cumulative losses in 42 scenarios. Each row shows the summary statistics for 100 Monte Carlo replication runs. A star $(\star)$ indicates the best policy within each group. The ranking criterion is the smallest absolute minimum value of the cumulative loss.

\begin{tabular}{|c|c|c|c|c|c|c|c|c|}
\hline \multicolumn{9}{|c|}{ Recession cumulative loss } \\
\hline Parameters & Scenario & Obs. & Min & $25 \%$ & Median & Mean & $75 \%$ & Max \\
\hline \multirow{7}{*}{$\alpha=1 \beta=0$} & $\mathrm{~A}(=\mathrm{I})$ & 773 & -82570 & -3225 & -3225 & -4872 & -1550 & -844.1 \\
\hline & $\mathrm{B}$ & 780 & -64680 & -3116 & -3116 & -4773 & -1549 & -877.9 \\
\hline & $\mathrm{C}$ & 796 & -58420 & -3068 & -3068 & -5127 & -1601 & -811.1 \\
\hline & $\mathrm{D} \star$ & 759 & -11110 & -2608 & -2608 & -2348 & -1479 & -860.6 \\
\hline & $\mathrm{E}$ & 848 & -56890 & -3648 & -3648 & -4345 & -1580 & -901.8 \\
\hline & $\mathrm{F}$ & 716 & -12910 & -2815 & -2815 & -2466 & -1499 & -864.4 \\
\hline & $\mathrm{G}$ & 817 & -48560 & -3864 & -3864 & -4440 & -1615 & -875.4 \\
\hline \multirow[t]{7}{*}{$\alpha=1 \beta=0.1$} & $\mathrm{~A}$ & 774 & -79040 & -3055 & -3055 & -4974 & -1623 & -816.5 \\
\hline & B & 745 & -67090 & -3085 & -3085 & -4611 & -1577 & -840 \\
\hline & $\mathrm{C}$ & 774 & -66990 & -3152 & -3152 & -5238 & -1597 & -861.5 \\
\hline & $\mathrm{D} \star$ & 754 & -11110 & -2609 & -2609 & -2346 & -1479 & -860.6 \\
\hline & $\mathrm{E}$ & 859 & -46250 & -3444 & -3444 & -4279 & -1606 & -819.2 \\
\hline & $\mathrm{F}$ & 716 & -12910 & -2815 & -2815 & -2466 & -1499 & -864.4 \\
\hline & G & 780 & -48560 & -3725 & -3725 & -4425 & -1554 & -757.9 \\
\hline \multirow[t]{7}{*}{$\alpha=1 \beta=1$} & $\mathrm{~A} \star(=\mathrm{H})$ & 437 & -4625 & -2041 & -2041 & -1812 & -1365 & -872.1 \\
\hline & $\mathrm{B}$ & 481 & -4991 & -2150 & -2150 & -1845 & -1368 & -919.1 \\
\hline & $\mathrm{C}$ & 460 & -6541 & -1984 & -1984 & -1751 & -1366 & -850.5 \\
\hline & $\mathrm{D}$ & 783 & -10170 & -2795 & -2795 & -2438 & -1538 & -788.9 \\
\hline & $\mathrm{E}$ & 604 & -8454 & -2250 & -2250 & -1916 & -1403 & -741.7 \\
\hline & $\mathrm{F}$ & 725 & -13280 & -2714 & -2714 & -2446 & -1503 & -862.4 \\
\hline & $\mathrm{G}$ & 571 & -11140 & -2186 & -2186 & -1900 & -1400 & -163.4 \\
\hline \multirow[t]{7}{*}{$\alpha=8 \beta=0$} & $\mathrm{~A}$ & 781 & -29340 & -2728 & -2728 & -3034 & -1548 & -330.2 \\
\hline & $\mathrm{B}$ & 731 & -50770 & -2661 & -2661 & -2890 & -1489 & -765 \\
\hline & $\mathrm{C}$ & 758 & -45760 & -2475 & -2475 & -2817 & -1486 & -774.6 \\
\hline & $\mathrm{D} \star$ & 762 & -11110 & -2663 & -2663 & -2355 & -1481 & -860.6 \\
\hline & $\mathrm{E}$ & 848 & -45940 & -3840 & -3840 & -4246 & -1576 & -798.3 \\
\hline & $\mathrm{F}$ & 719 & -12910 & -2808 & -2808 & -2470 & -1503 & -864.4 \\
\hline & G & 798 & -46400 & -3759 & -3759 & -4416 & -1612 & -967.7 \\
\hline \multirow[t]{7}{*}{$\alpha=8 \beta=0.1$} & $\mathrm{~A}$ & 760 & -48800 & -2708 & -2708 & -2792 & -1473 & -852.1 \\
\hline & $\mathrm{B}$ & 781 & -31110 & -2585 & -2585 & -2691 & -1455 & -851.9 \\
\hline & $\mathrm{C}$ & 726 & -44470 & -2625 & -2625 & -2995 & -1480 & -754.9 \\
\hline & $\mathrm{D} \star$ & 762 & -11110 & -2663 & -2663 & -2355 & -1481 & -860.6 \\
\hline & $\mathrm{E}$ & 784 & -40430 & -4065 & -4065 & -4459 & -1632 & -895.6 \\
\hline & $\mathrm{F}$ & 723 & -12910 & -2808 & -2808 & -2468 & -1506 & -864.4 \\
\hline & G & 788 & -49550 & -4237 & -4237 & -4529 & -1604 & -829.1 \\
\hline \multirow[t]{7}{*}{$\alpha=8 \beta=1$} & $A \star$ & 431 & -4625 & -2036 & -2036 & -1802 & -1359 & -872.1 \\
\hline & $\mathrm{B}$ & 481 & -4991 & -2150 & -2150 & -1845 & -1368 & -919.1 \\
\hline & $\mathrm{C}$ & 455 & -6541 & -1985 & -1985 & -1751 & -1370 & -850.5 \\
\hline & $\mathrm{D}$ & 783 & -10170 & -2782 & -2782 & -2430 & -1536 & -788.9 \\
\hline & $\mathrm{E}$ & 604 & -8454 & -2250 & -2250 & -1916 & -1403 & -741.7 \\
\hline & $\mathrm{F}$ & 714 & -13280 & -2679 & -2679 & -2439 & -1483 & -862.4 \\
\hline & $\mathrm{G}$ & 576 & -11140 & -2185 & -2185 & -1900 & -1398 & -163.4 \\
\hline
\end{tabular}




\section{References}

Abiad, A., Dell'Ariccia, G., Li, B., Mar. 2011. Creditless Recoveries. IMF Working Papers 11/58, International Monetary Fund.

Acharya, V. V., Eisert, T., Eufinger, C., Hirsch, C. W., June 20 2016. Whatever it takes: The real effects of unconventional monetary policy. Tech. rep., CEPR Working Paper.

Admati, A., Hellwig, M., 2013. The Bankers' New Clothes: What's Wrong with Banking and What to Do about It. The University Press Group, West Sussex, UK.

Ang, J. B., 2008. A survey of recent developments in the literature of finance and growth. Journal of Economic Surveys 22 (3), 536 - 576.

Arestis, P., Demetriades, P. O., 1997. Financial development and economic growth: Assessing the evidence. Economic Journal 107 (442), 783 - 799.

Ashraf, Q., Gershman, B., Howitt, P., 2011. Banks, market institution, and macroeconomic performance: An agent-based computational analysis. NBER Working Paper No. 17102, National Bureau of Economic Research.

Balanescu, T., Cowling, A., Georgescu, H., Gheorghe, M., Holcombe, M., Vertan, C., 1999. Communicating stream X-machine systems are no more than X-machines. Journal of Universal Computer Science 5 (9), 494-507.

Bank of England, April 2016. Understanding and measuring finance for productive investment. Discussion paper, Bank of England.

Bencivenga, V. R., Smith, B. D., 1991. Financial intermediation and endogenous growth. Review of Economic Studies 58 (2), 195 - 209.

Bencivenga, V. R., Smith, B. D., 1993. Some consequences of credit rationing in an endogenous growth model. Journal of Economic Dynamics and Control 17 (1-2), 97 - 122.

Bernanke, B., Gertler, M., 1989. Agency costs, net worth, and business fluctuations. American Economic Review 79 (1), $14-31$.

Bernanke, B., Gertler, M., 1990. Financial fragility and economic performance. Quarterly Journal of Economics 105 (1), 87 - 114.

Bernanke, B. S., August 27 2010. The Economic Outlook and Monetary Policy. Speech, Federal Reserve Bank of Kansas City Economic Symposium, Jackson Hole, Wyoming.

Bezemer, D., November 2014. Schumpeter might be right again: the functional differentiation of credit. Journal of Evolutionary Economics 24 (5), 935-950.

Boyd, J. H., Smith, B. D., 1998. The evolution of debt and equity markets in economic development. Economic Theory 12 (3), 519 - 560.

Brav, A., Graham, J. R., Harvey, C., Michaely, R., 2005. Payout policy in the 21st century. Journal of Financial Economics 77 (3), 483-527.

Bry, G., Boschan, C., 1971. Cyclical Analysis of Time Series: Selected Procedures and Computer Programs. National Bureau of Economic Research. 
Caballero, R. J., 2010. Macroeconomics after the crisis: Time to deal with the pretense-ofknowledge syndrome. Journal of Economic Perspectives 24 (4), 85-102.

Caballero, R. J., Hoshi, T., Kashyap, A. K., 2008. Zombie Lending and Depressed Restructuring in Japan. American Economic Review 98 (5), 1943-77.

Caiani, A., Godin, A., Caverzasi, E., Gallegati, M., Kinsella, S., Stiglitz, J. E., Aug. 2016. Agent Based-Stock Flow Consistent Macroeconomics: Towards a Benchmark Model. Journal of Economic Dynamics and Control 69, 375-408.

Canuto, O., Cavallari, M., 21 May 2013. Integrating monetary policy and macroprudential regulation. Tech. rep., VoxEU.

Cerra, V., Saxena, S. C., March 2008. Growth Dynamics: The Myth of Economic Recovery. American Economic Review 98 (1), 439-57.

Claessens, S., Kose, M. A., Terrones, M. E., 2012. How do business and financial cycles interact? Journal of International Economics 87 (1), 178-190.

Coakley, S., Chin, L.-S., Holcomb, M., Greenough, C., Worth, D., 2012a. Flexible Large-scale Agent Modelling Environment (FLAME). Tech. rep., University of Sheffield and Rutherford Appleton Laboratories, STFC, License: Lesser GPL v3. Software available from: http:// www.flame.ac.uk/ and http://github/FLAME-HPC.

Coakley, S., Gheorghe, M., Holcombe, M., Chin, S., Worth, D., Greenough, C., 2012b. Exploitation of high performance computing in the flame agent-based simulation framework. In: Proceedings of the 2012 IEEE 14th International Conference on High Performance Computing and Communications. pp. 538-545.

Coakley, S., Smallwood, R., Holcombe, M., 2006. Using X-machines as a formal basis for describing agents in agent-based modelling. In: Agent-Directed Simulation, Proceedings of the SpringSim 2006 Conference.

Cochrane, J. H., 2014. Toward a run-free financial system. In: Baily, M. N., Taylor, J. B. (Eds.), Across the Great Divide: New Perspectives on the Financial Crisis. Publication No. 652. Hoover institution Press, Ch. 10, pp. 197-250.

Dawid, H., Gemkow, S., Harting, P., van der Hoog, S., Neugart, M., 2017. Agent-based macroeconomic modeling and policy analysis: the Eurace@Unibi model. In: Chen, S.-H., Kaboudan, M. (Eds.), Handbook on Computational Economics and Finance. Oxford University Press (In press), Oxford.

Dawid, H., Harting, P., van der Hoog, S., Neugart, M., 2016. A Heterogeneous Agent Macroeconomic Model for Policy Evaluation: Improving Transparency and Reproducibility. Bielefeld Working Papers in Economics and Managment No. 06-2016 .

Dell'Ariccia, G., Igan, D., Laeven, L., Tong, H., 2014. Policies for macro-financial stability: dealing with credit booms and busts. In: Claessens, S., Kose, M., Laeven, L., Valencia, F. (Eds.), Financial Crises: Causes, Consequences, and Policy Responses. International Monetary Fund, Washington, DC, Ch. 11, pp. 325-364.

Delli Gatti, D., Desiderio, S., Gaffeo, E., Cirillo, P., Gallegati, M., 2011. Macroeconomics from the Bottom-Up. Springer-Verlag, London. 
Delli Gatti, D., Gaffeo, E., Gallegati, M., Giulioni, G., Palestrini, A., 2008. Emergent Macroeconomics: An Agent-Based Approach to Business Fluctuations. Springer-Verlag, London.

Delli Gatti, D., Gallegati, M., Giulioni, G., Palestrini, A., 2003. Financial fragility, patterns of firms' entry and exit and aggregate dynamics. Journal of Economic Behavior \& institution $51(1), 79-97$.

Demirguc-Kunt, A., Ayyagari, M., Maksimovic, V., 2015. SME Contribution to Employment. Worldbank dataset, Worldbank, Retrieved on 2 Sept 2015 from: http://go.worldbank.org/ DMD75EFBB0,

Dosi, G., Fagiolo, G., Napoletano, M., Roventini, A., Treibich, T., 2015. Fiscal and monetary policies in complex evolving economies. Journal of Economic Dynamics and Control 52, 166189.

Douglas, P. H., Hamilton, E. J., Fisher, I., King, W. I., Graham, F. D., Whittlesey, C. R., July 1939. A program for monetary reform. Tech. rep., Unpublished draft manuscript.

Dow, S., Johnsen, G., Montagnoli, A., March 2015. A critique of full reserve banking. Working Papers 2015008, The University of Sheffield, Department of Economics.

Fisher, I., 1933. The debt-deflation theory of great depressions. Econometrica 1, 337.

Gemkow, S., Harting, P., van der Hoog, S., May 2014. Eurace@Unibi Model v1.0 Source Code. Tech. rep., Bielefeld University, Bielefeld, License: EULA. doi: 10.4119/unibi/2900767.

Gemkow, S., van der Hoog, S., 2012. R Data Analysis Scripts. Tech. rep., Bielefeld University, Bielefeld, Unpublished. License: GPL v3.

Goodhart, C., Sunirand, P., Tsomocos, D., 2005. A model to analyse financial fragility. Economic Theory 27 (1), 107-142.

Greenwood, J., Jovanovic, B., 1990. Financial development, growth, and the distribution of income. Journal of political economy 98 (5(1)), 1076-1107.

Harding, D., Pagan, A., Mar. 2002. Dissecting the cycle: a methodological investigation. Journal of Monetary Economics 49 (2), 365-381.

HM Treasury, 22 June 2010. Glossary of Treasury terms. Tech. rep., The National Archives, Retrieved on 28 August 2015 from: http://webarchive.nationalarchives.gov.uk/ 20130129110402/http://www.hm-treasury.gov.uk/junebudget_glossary.htm.

Holcombe, M., 1988. X-machines as a basis for dynamic system specification. Software Engineering Journal 3 (2), 69-76.

Holcombe, M., Ipate, F., 1998. Correct Systems: Building A Business Process Solution. SpringerVerlag, London.

van der Hoog, S., 2016b. Data for the paper: The Limits to Credit Growth. Bielefeld University, Bielefeld.

van der Hoog, S., Dawid, H., 2017. Bubbles, crashes and the financial cycle: The impact of banking regulation on deep recessions. Macroeconomic Dynamics (In press) . 
Ipate, F., 2004. Complete deterministic stream X-machine testing. Formal Aspects of Computing $16,374-386$.

Jordà, O., Schularick, M., Taylor, A., 2013. When credit bites back. Journal of Money, Credit and Banking 45 (s2), 3-28.

Kehris, E., Eleftherakis, G., Kefalas, P., 2000. Using X-machines to model and test discrete event simulation programs. In: Systems and Control: Theory and Applications. World Scientific, pp. $163-168$.

Kehris, E., Stamatopoulou, I., Gheorghe, M., 2005. A formal modelling framework for developing multi-agent systems with dynamic structure and behaviour. In: Multi-Agent Systems and Applications IV: Proceedings of the 4th International Central and Eastern European Conference on Multi-Agent Systems (CEEMAS'05). Lecture Notes in Artificial Intelligence, 3690. Springer-Verlag, pp. 122-131.

King, R., Levine, R., 1993. Finance and growth: Schumpeter might be right. Quarterly Journal of Economics 108 (3), 717-737.

Kirman, A., 2010. The economic crisis is a crisis for economic theory. CESifo Economic Studies $56,498-535$.

Klein, M. C., 27 March 2013. The best way to save banking is to kill it. [blog]. Tech. rep., Bloombergview, Retrieved on 29 March 2015 from: http://www.bloombergview.com/ articles/2013-03-27/the-best-way-to-save-banking-is-to-kill-it.

Koo, R. C., 2009. The Holy Grail of Macroeconomics - Lessons from Japan's Great Recession. John Wiley \& Sons, New Jersey.

Krug, S., Lengnick, M., Wohltmann, H.-W., 2015. The impact of basel iii on financial (in)stability: an agent-based credit network approach. Quantitative Finance 15 (12), 19171932 .

Laina, P., August 2015. Proposals for Full-Reserve Banking: A Historical Survey from David Ricardo to Martin Wolf. Working Paper, Department of Political and Economic Studies, University of Helsinki, Finland.

Lavoie, M., Godley, W., 2006. Features of a realistic banking system within a Post-Keynesian stock-flow consistent model. In: Setterfield, M. (Ed.), Complexity, Endogenous Money and Macroeconomic Theory: Essays in Honour of Basil J. Moore. Edward Elgar: Cheltenham, pp. $251-268$.

Lazonick, W., April 2014. Stock buybacks: From retain-and-reinvest to downsize-and-distribute. Report, Brooking Institute: Center for Effective Public Management, Washington, D.C.

Le Heron, E., Mouakil, T., 2008. A Post-Keynesian stock-flow consistent model for dynamic analysis of monetary policy shock on banking behaviour. Metroeconomica 59 (3), 405-440.

Levine, R., Loayza, N., Beck, T., 2000. Financial intermediation and growth: Causality and causes. Journal of monetary economics 46 (1), 31-77.

Loayza, N., Rancière, R., 2006. Financial development, financial fragility, and growth. Journal of Money, Credit and Banking 38 (4), 1051-1076. 
McKinnon, R., 1973. Money and Capital in Economic Development. Brookings institution, Washington, DC.

Minsky, H. P., 1978. The financial instability hypothesis: A restatement. Hyman P. Minsky Archive Paper 180, 541-552.

Minsky, H. P., 1986. Stabilizing an Unstable Economy. Yale University Press, (2nd edition 2008, McGraw-Hill:New York).

Minsky, H. P., 1992. The financial instability hypothesis. Economics Working Paper Archive wp74, The Jerome Levy Economics Institute of Bard College.

Minsky, H. P., Papadimitriou, D. B., Phillips, R. J., Wray, L. R., Dec. 1992. Community Development Banks. Economics Working Paper Archive wp83, The Jerome Levy Economics Institute of Bard College.

Miyajima, H., Yafeh, Y., 2007. Japan's banking crisis: An event-study perspective. Journal of Banking \& Finance 31 (9), 2866-2885.

National Bureau of Economic Research, 12 October 2007. Business cycle expansions and contractions. Tech. rep., National Bureau of Economic Research.

Phillips, R., July 1992a. Credit Markets and Narrow Banking. Economics Working Paper Archive wp77, The Jerome Levy Economics Institute of Bard College.

Phillips, R., June 1992b. The Chicago Plan and New Deal Banking Reform. Economics Working Paper Archive wp76, The Jerome Levy Economics Institute of Bard College.

Popoyan, L., Napoletano, M., Roventini, A., 12 2015. Taming Macroeconomic Instability: Monetary and Macro Prudential Policy Interactions in an Agent-Based Model. LEM Papers Series 2015/33, Laboratory of Economics and Management (LEM), Sant'Anna School of Advanced Studies, Pisa, Italy.

R Development Core Team, 2008. R: A language and environment for statistical computing. Tech. rep., R Foundation for Statistical Computing, Vienna, Austria.

URL http://www.R-project.org

Rancière, R., Tornell, A., Westermann, F., 2008. Systemic crises and growth. Quarterly Journal of Economics 123 (1), 359-406.

Reinhart, C. M., Rogoff, K. S., May 2009. The aftermath of financial crises. American Economic Review 99 (2), 466-72.

Ryan-Collins, J., Greenham, T., Werner, R., Jackson, A., 2014. Where Does Money Come From?: A Guide to the UK Monetary \& Banking System. New Economics Foundation, (2nd ed.).

Schularick, M., Taylor, A. M., 2012. Credit booms gone bust: Monetary policy, leverage cycles, and financial crises, 1870-2008. American Economic Review 102 (2), 1029-61.

Schuman, M., 28 August 2015. Zombie factories stalk the sputtering Chinese economy. Tech. rep., The New York Times, Retrieved from: http://www.nytimes.com/2015/08/30/business/ international/zombie-factories-stalk-the-sputtering-chinese-economy.html. 
Schumpeter, J. A., 1934. The Theory of Economic Development: An Inquiry into Profits, Capital, Credit, Interest, and the Business Cycle. Harvard University, Cambridge, Mass.

Shaw, E., 1973. Financial Deepening in Economic Development. New York : Oxford University Press.

Summers, L. H., 2014. U.S. Economic Prospects: Secular Stagnation, Hysteresis, and the Zero Lower Bound. Business Economics 49 (2), Keynote address at the NABE Policy Conference, February 24, 2014.

Terrones, M., April 2004. Are credit booms in emerging markets a concern? In: World Economic Outlook. Washington, DC: International Monetary Fund, Ch. 4.

Werner, R., 2003. Princes of the Yen: Japan's Central Bankers and the Transformation of the Economy. East Gate Books.

Werner, R., 2005. New Paradigm in Macroeconomics: Solving the riddle of japanese macroeconomic performance. Palgrave McMillan.

Zingales, L., 2015. Does finance benefit society? NBER Working Paper No. 20894, National Bureau of Economic Research. 